Article

\title{
Application of MICMAC, Fuzzy AHP, and Fuzzy TOPSIS for Evaluation of the Maintenance Factors Affecting Sustainable Manufacturing
}

\author{
Małgorzata Jasiulewicz-Kaczmarek 1,*iD, Katarzyna Antosz 2,*D, Ryszard Wyczółkowski ${ }^{3}$, \\ Dariusz Mazurkiewicz ${ }^{4}\left(\mathbb{D}\right.$, Bo Sun ${ }^{5}$ (D), Cheng Qian ${ }^{5}$ and Yi Ren ${ }^{5}$
}

1 Faculty of Management Engineering, Poznan University of Technology, ul. Prof. Rychlewskiego 2, 60-965 Poznan, Poland

2 Faculty of Mechanical Engineering and Aeronautics, Rzeszow University of Technology, Powstańców Warszawy 8, 35-959 Rzeszow, Poland

3 Faculty of Organization and Management, Silesian University of Technology, 26th Roosevelta Str, 41-800 Zabrze, Poland; ryszard.wyczolkowski@polsl.pl

4 Mechanical Engineering Faculty, Lublin University of Technology, ul. Nadbystrzycka 36, 20-618 Lublin, Poland; d.mazurkiewicz@pollub.pl

5 School of Reliability and Systems Engineering, Beihang University, No.37 XueYuan RD, Haidian, Beijing 100191, China; sunbo@buaa.edu.cn (B.S.); cqian@buaa.edu.cn (C.Q.); renyi@buaa.edu.cn (Y.R.)

* Correspondence: malgorzata.jasiulewicz-kaczmarek@put.poznan.pl (M.J.-K.); katarzyna.antosz@prz.edu.pl (K.A.)

check for updates

Citation: Jasiulewicz-Kaczmarek, M.; Antosz, K.; Wyczółkowski, R.; Mazurkiewicz, D.; Sun, B.; Qian, C.; Ren, Y. Application of MICMAC, Fuzzy AHP, and Fuzzy TOPSIS for Evaluation of the Maintenance Factors Affecting Sustainable Manufacturing. Energies 2021, 14, 1436. https://doi.org/10.3390/ en14051436

Academic Editor: Aleksy Kwilinski

Received: 4 February 2021

Accepted: 2 March 2021

Published: 5 March 2021

Publisher's Note: MDPI stays neutral with regard to jurisdictional claims in published maps and institutional affiliations.

Copyright: (c) 2021 by the authors. Licensee MDPI, Basel, Switzerland. This article is an open access article distributed under the terms and conditions of the Creative Commons Attribution (CC BY) license (https:// creativecommons.org/licenses/by/ $4.0 /)$.
Abstract: This paper presents an empirical study on the impact of maintenance function on more sustainable manufacturing processes. The work methodology comprises four stages. At first, ten factors of maintenance activities from a sustainable manufacturing point of view were identified. Then, in the second stage, the matrix of crossed impact multiplications applied to a classification (MICMAC) was carried out to categorize these factors based on their influence and dependence values. In the third stage, the criteria for evaluation of maintenance factors were defined, then the fuzzy analytic hierarchy process (F-AHP) was applied to determine their relative weights. In the last stage, the results of MICMAC and F-AHP analyses were used as inputs for the fuzzy technique for order preference by similarity to ideal solution (F-TOPIS) to generate aggregate scores and selection of the most important maintenance factors that have an impact on sustainable manufacturing processes. A numerical example is provided to demonstrate the applicability of the approach. It was observed that factors "Implementation of preventive and prognostic service strategies", "The usage of M\&O data collection and processing systems", and "Modernization of machines and devices" are the major factors that support the realization of sustainable manufacturing process challenges.

Keywords: sustainable maintenance; maintenance factors; maintenance hybrid analysis; MICMAC analysis; fuzzy AHP; fuzzy TOPSIS

\section{Introduction}

In the area of manufacturing management, researchers and practitioners are facing new challenges, namely, the Sustainable Development Goals. Sustainable Development Goals are an agenda created by the United Nations [1] that tackle the sustainable environment issues for the future world.

In the manufacturing industry, the concept of sustainability has been adopted and is known as sustainable manufacturing or sustainable production. Sustainable manufacturing is defined in many ways, i.e., as a paradigm set of technologies or systems. According to the literature review conducted by [2], the definition provided by the US Department of Commerce in 2008: "the creation of products through processes that minimize both negative environmental impacts and consumption of energy and natural resources, being also safe for employees, communities, consumers and economically viable" is mostly used. 
The goal of sustainable manufacturing is to obtain a balance between environmental, social, and economic dimensions to meet stakeholder requirements [3] and achieve a competitive advantage [4]. In [5], the authors believe that apart from triple bottom line (TBL) factors, technology, education, ethics, and responsibility are the key factors enabling sustainable manufacturing. According to [6], six main aspects of sustainable production are energy and material use (resources), natural environment, social justice and community development, economic performance, workers, and products.

Improvement in sustainable manufacturing performance requires searching for opportunities in order to reduce waste and add value from the perspective of all sustainability dimensions $[3,4,6]$.

According to [7-10], the success of sustainable manufacturing processes in improving economic, social and environmental performance can be achieved through their integration with maintenance activities. Reference [7] pointed out that "maintenance as part of the circular economy can be considered, first, as an enabling system to sustain the artefact throughout its life cycle, then as a key tool to keep the regeneration potential of this artefact, and finally, as a target system that must be sustainable". According to [8] "The maintenance activity is by nature an important lever for action on the sustainability of production systems". Recently, [9] has pointed out that "organisations must become more aware of the importance of addressing maintenance as a set of processes that (1) must sustain equipment/assets during their operation in order to guarantee compliant production processes for manufactured products and reduce industrial impacts on the economy, society and the surrounding environment and (2) must be a sustainable business function in order to limit the impacts generated during maintenance activities".

The review of the literature from the recent years shows that the issue of the relationship between maintenance management and the overall efficiency of production systems in terms of sustainable development is increasingly addressed. Generally, this research is conducted primarily in two areas.

The first area of the research focuses on the development of measures and indicators for the assessment of sustainable maintenance as well as the design of assessment models [11-13]. From the scientific point of view, the search for new measures and indicators expands the scope of our knowledge about the maintenance impact on the implementation of sustainable manufacturing challenges. From the practical point of view, it shows not only a maintenance impact on sustainability, but it also creates a new framework for maintenance goals and the method for their evaluation. The works in the first area analyze impacts and dependencies between measures and indicators and what may constitute the basis for building action scenarios and determining priorities [13]. However, factors influencing these actions are not analyzed.

The next area of the research is focused on the impact and contributions of maintenance functions to more sustainable operations in manufacturing companies. These studies are based on interviews in which respondents (managers and employees of maintenance; production; human resources (HR); and safety, health, and environment (SHE) departments) explain their companies' achievements in reducing the use of resources (especially hazardous or harmful materials, water, and energy), the emitted pollution, and the generated waste in minimizing environmental risks, etc. $[9,10]$. These studies present the impacts and contributions of maintenance functions on more sustainable manufacturing operations, challenges faced by maintenance managers as well as the factors that should be taken into account in order to strengthen maintenance activities, and thus meet the requirements set by company managers. Nevertheless, none of the analyzed studies in this area have been conducted in-depth considering the factors influencing the maintenance capability/ability to meet the challenges of sustainable production. However, the need for such research is emphasized.

A certain research gap between the two areas of research is observed. The research gap concerns the identification of maintenance factors significantly influencing the implementation of sustainable manufacturing challenges, determining the relationships between them 
and recommending the priorities of actions aimed at increasing the sustainability results. The research in this area was carried out by [14,15]. In the first study, maintenance factors from a tactical perspective were identified, and on the basis of the research conducted in 58 companies, their importance was assessed. Then, using the interpretive structural modelling (ISM) and matrix of crossed impact multiplications applied to a classification (MICMAC) methods, the research in a company was performed, and the relationships between the factors were determined. In the second paper, based on the literature research, 14 factors out of maintenance factors from a strategic perspective were identified. Then, ISM and fuzzy MICMAC were applied in order to develop structural relationships among the factors and categorize these factors based on their driving and dependence values. Finally, with the technique for ordering preferences by similarity to an ideal solution (TOPSIS) approach, the factors were ranked based on their importance from the strategy perspective of maintenance management. Despite its significant cognitive value, the study does not specify any elements significant for the approach, including the criteria for ranking factors, which makes it difficult to formulate an interpretation and a significant conclusion.

The maintenance contribution in the realization of sustainability challenges is dependent on the operational and business context of a company; thus, companies need to identify factors affecting sustainability performance based on their specific processes, business needs, and goals. Therefore, in order to support maintenance decision-makers in attaining sustainability and to point out the way of maintenance function contribution to sustainable manufacturing, main maintenance factors affecting sustainable manufacturing should be identified and analyzed. The factors that are appropriate to their operational context should be selected.

In this context, the research challenges in the area under consideration concern multicriteria decision-making problems. One means of dealing with these problems are the MCDM (multi-criteria decision-making) models. These methods have been extensively used in various studies in maintenance management [16,17]. Decision making in the selection of maintenance factors influencing sustainable production is very complex due to many factors related to the industry, company-specific processes, needs, and business goals. In order to choose the most appropriate maintenance factors, the MICMAC analysis in this research was proposed. MICMAC allows one to determine interactions between factors and by grouping factors into clusters it helps to reduce the size of some complex problems, making them more manageable and revealing hidden relationships between various considered factors. After the most important maintenance factors were identified, the fuzzy AHP (analytical hierarchy process) method and fuzzy TOPSIS (technique for order preference by similarity to ideal solution) were used to determine the right judgment of maintenance factors affecting sustainable manufacturing based on the company specific requirements. In this respect, F-AHP can be very useful in involving several decisionmakers with multiple conflicting criteria to reach a consensus in the decision-making process. On the other side, the F-TOPSIS technique is used to calculate alternatives ratings. The choice of the TOPSIS is due to its capability of ranking a wide number of alternatives. This approach can be considered as a driver in implementing the alternative that represents the best trade-off according to the various considered criteria.

Considering the above, the aim of this paper is to analyze the maintenance factors influencing the implementation of sustainable manufacturing challenges from a tactical perspective, to determine the relationships between them, and to rank them taking into account the specificity of an operational context of an enterprise. This paper is a continuation of the previously undertaken work presented in [14].

Given the purpose above, the paper is organized as follows (Figure 1): Section 2 presents an overview of the maintenance in the sustainable manufacturing environment; Section 3 describes the proposed research methodology, Section 4 describes the maintenance factors affecting sustainable manufacturing and presents the discussion of the results obtained from applying the proposed methodology in the company, and Section 5 concludes the paper. 


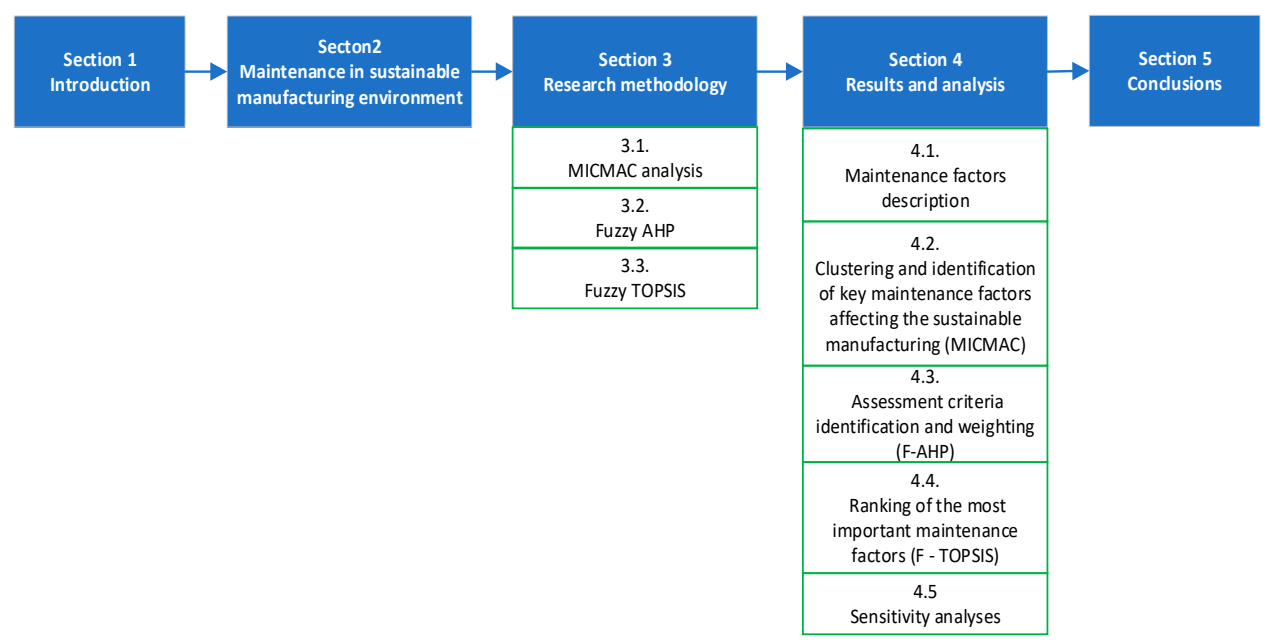

Figure 1. Outline of the structure of the paper.

\section{Maintenance in Sustainable Manufacturing Environment}

By definition, maintenance is the "combination of all technical, administrative and managerial actions during the life cycle of an item intended to retain it, or restore it to a state in which it can perform the required function" [18]. From this definition, it follows that maintenance is a complex set of activities that cover the entire structure and organization of a manufacturing company [19].

In recent years, the importance of sustainability issues in maintenance management has been recognized $[9,10,13,20]$. Yan [20] stressed that "sustainability-based maintenance management would be one of the most important strategies for sustainable development". Today, maintenance is more than just repairing machines and devices. It helps the manufacturing companies to achieve their sustainability objectives and helps in increasing their competitiveness through improved availability, quality, and overall ability to meet demand. According to Takata [21], the aim of maintenance is to "maximise value generated by operations rather than minimising the maintenance cost".

According to [18], maintenance activities must be considered in all stages of the life cycle of the machine. The role of maintenance in the phases of the product lifecycle leads to the availability and reliability of equipment, improves environmental efficiency, and achieves safety [22]. From a practical point of view, each stage of machines and devices life cycle should be supported by maintenance from machine design to end-of-life [10,22-25]. According to [26], adopting a life cycle perspective is important for cascading business sustainability policies to production assets.

On the other hand, the contribution of maintenance to a more sustainable manufacturing system can be seen from the perspective of the TBL approach, i.e., economic, environmental, and social issues.

Regarding the economic dimension of TBL, many studies indicate improvement regarding efficiency and effectiveness through a new way of maintenance process realization and resource utilization. Research conducted by [27] pointed out that in the life cycle cost breakdown structure of a plant, operating and maintenance costs account for more than $60 \%$. By providing information regarding historical reliability, expected useful life, failure rates, and training maintenance personnel, maintenance activities could bring reductions in operating costs, productivity improvements, higher reliability, and contributions to product competitiveness $[9,10]$. This would indirectly increase the company's overall profits and enable investments in new equipment or new technologies.

Regarding the environmental dimension, the main aspect is the resource (water, air, energy, materials) efficiency, air emission reductions, and land conservation; depending on a specific operational context these would require the involvement of a maintenance function. Energy consumption and efficiency aspects have been more often addressed in 
maintenance literature [10,28-31]. A maintenance department has no formal responsibilities over energy management. Collaboration with an energy management department and the use of an energy consumption analysis as a technique for the condition-based maintenance, can support the company in better energy management. Ill-defined maintenance practices for manufacturing machinery lead to hazardous emissions [32], production waste due to system malfunctions $[9,10]$, ineffective resource consumption, and waste of the stored materials [9,10,32]. According to [33], "In mitigating negative effects in the environment, current maintenance practice must be considered, not just for the reduction of its own direct impact but also for its potential contribution to a more sustainable lifecycle for the manufacturing operation, its products and related services". A continuous focus on reducing waste in maintenance activities; minimizing material, water, and energy usage; and avoiding hazardous substance usage results in lowering costs, improving maintenance processes, and increasing the maintenance quality.

Lastly, according to the impact on the social dimension, literature links to plant safety and human safety as well as communication and collaboration with other company functions as a main means to avoid undesired failures and minimize the consequences of failures $[9,10,14,34]$. Maintenance work is usually critical to operator's health; therefore, the maintenance department should work toward the creation of a safe working environment [34]. According to [10,14], good communication and cooperation between the maintenance department and the Research and Development (R\&D) departments as well as the quality and production departments lead to a better understanding of the role of maintenance in a company. Maintenance personnel are able to propose suggestions of a product design, specific modifications to the equipment, and contributions to the preparation of specifications for the equipment acquisition. A good relationship with HR can be developed with adequate training for the maintenance staff. The next issue of the social dimension of sustainability is related to relationships and the fulfilment of the expectations of external stakeholders. Important external maintenance stakeholders are: the equipment and spare parts suppliers, service providers, certification bodies as well as the local community. According to [35] in maintenance management, "social implications" should be made "mandatory" instead of "if applicable".

The transition to sustainable maintenance requires changes in the way decisions are made, from a traditional approach based primarily on financial aspects to a more holistic approach that includes social and environmental aspects [13]. At the same time, as with any activity, this change should be made as efficiently as possible, with efforts and resources directed to where they will have the greatest impact. Therefore, an important step for any company to support a sustainable manufacturing strategy for the successful improvement of a maintenance system is to identify the critical success factors of maintenance management which significantly affect the sustainability of this activity

\section{Research Methodology}

The research methodology consists of four stages. The first stage describes the maintenance factors affecting sustainable manufacturing from a tactical point of view based on [14]. Then, in the second stage, the MICMAC method was used to analyze these factors. The MICMAC method developed by Duperrin and Godet [36] allowed the determination of direct and indirect interactions between factors based on a defined direct impact matrix developed by experts. Moreover, the method, using the property of matrix multiplication, allowed the identification of indirect influences that are difficult to identify by experts. Additionally, potential influences that may arise between the variables in the future were taken into account. After that, the maintenance factors based on their influence and dependence power were grouped into four clusters. By grouping the factors into clusters, it was possible to decrease the size of a complex problem, to reduce the number of factors, and thus to identify the key maintenance factors affecting sustainable manufacturing, which were the input for the F-TOPSIS method. Even if widely used, the MICMAC method has some drawbacks $[14,15,37,38]$. Firstly, although the decisions were made by agreement, 
the information that was used in the analysis came from different experts with different knowledge and experience, so the information was subjective and imprecise. Secondly, the MICMAC method based on impact and relationship values identified the key maintenance factors but did not rank them based on their relative importance from the sustainability point of view.

One means of dealing with the problem of ranking the maintenance factors based on their relative importance from the sustainability point of view is the MCDM models. These methods are extensively used in various studies in the maintenance management area $[16,17]$. Our proposed methodology integrates two methods. Firstly (the third stage of our methodology), the fuzzy analytic hierarchy process (F-AHP) is used to determine the relative weights of the evaluation criteria of the maintenance factors. Secondly (the fourth stage of our methodology), the fuzzy TOPSIS method (F-TOPSIS) is applied to rank the maintenance factors.

When assessing the maintenance factors relevant to sustainability, various criteria and their weights play an important role in the decision-making process. Thus, the criteria for assessing maintenance factors should be defined at first, and then their weight should be determined. There is a variety of criteria that deserve consideration when evaluating maintenance factors from the point of view of sustainable manufacturing. Each company, based on its own long-term strategy, business needs and goals, and their specific processes, should define the criteria by which maintenance factors will be ranked. In order to choose these criteria, a company may use the criteria developed by [11-13]. After the assessment, the maintenance factors criteria were defined, and the fuzzy AHP for obtaining the criteria's relative weights was used. The F-AHP is an extension of the classic AHP method, developed by Saaty [39]. According to the literature survey conducted by the authors, this method is commonly used for calculating criteria weights and it has been successfully implemented in various areas [40-42]. The additional advantages of F-AHP are the ability to analyze multiple criteria, qualitative and quantitative data, and that it is easy to understand and use.

In the fourth stage of the methodology, the results of the F-AHP (criteria relative weights) and MICMAC (key maintenance factors) analyses are used as the input for the F-TOPIS method in order to rank the maintenance factors. The F-TOPSIS is an extension of the classical TOPSIS method developed by [43], regarding the principle that the chosen alternative should have the shortest distance from the ideal solution and the longest distance from the negative ideal solution. The ideal solution is a solution that maximizes the benefit criteria and minimizes the cost criteria. In the F-TOPSIS decision matrix, each alternative (factor) was assessed within the considered evaluation criteria, and, finally, the rank of the maintenance factors affecting sustainable manufacturing was determined. After that, a sensitivity analysis was performed. Such analysis tests the suitability of the model. Similar to the classic method, F-TOPSIS has been successfully applied in many areas $[44,45]$.

The brief descriptions of the MICMAC, F-AHP, and F-TOPSIS methods used in this research are presented in Sections 3.1-3.3, respectively.

Because the maintenance system is an open system and its results depend on the constant impact of changing environmental conditions, the weighting of the assessment criteria (F-AHP) and ranking maintenance factors (F-TOPIS) cannot be carried out in isolation from its stakeholders. Maintenance stakeholders in an enterprise are different organizational units, e.g., a production department, quality, occupational health and safety, environment, company manager, etc. Each maintenance stakeholder is likely to have different viewpoints representing the perception of dependence between maintenance factors and assessment criteria and their importance, as well as the rank of maintenance factors.

In order to ensure that the rank of maintenance factors being developed meets the needs and expectations of all stakeholders, it is critical to understand different viewpoints. Therefore, in order to determine the dependence between the maintenance factors (MICMAC analysis) and to determine the importance of the assessment criteria (F-AHP), 
maintenance stakeholders (representatives from various departments of a company) should work together. Working in one group and conducting discussions will enable experts from the company to understand the conditions of the functioning of a maintenance system from various perspectives, and it will prepare them to the second stage of research. In the second stage (F-TOPSIS), in order to rank maintenance factors, experts from a company should work in teams which represent different company departments (e.g., production, maintenance, SHE). This allows to identify differences on the perception of maintenance factors from the defined criteria. These recommendations were used in the research conducted in the case study company (Sections 4.2-4.4).

Because experts have different levels of cognitive vagueness (different experience and knowledge), linguistic variables should be used to determine the degree of the importance of assessment criteria and maintenance sustainability. Each expert assesses the criteria/rank of the factors by selecting appropriate "words" from a linguistic scale according to their expertise and experience. The obtained linguistic assessments of the criteria are converted into fuzzy values [46-48]. For this purpose, an appropriate membership function should be built, representing the adopted scale of linguistic assessments. The membership degree of the fuzzy set can be described with triangular, trapezoidal, Gaussian, and sigmoidal functions, or can be formed with different functions. Both triangular and trapezoidal fuzzy numbers could be used in this research. In the current research, triangular fuzzy numbers were used to transform linguistic terms into fuzzy values. Triangular fuzzy numbers are useful in promoting representation and information processing in a fuzzy environment and their computational simplicity [49,50]. According to the literature review [51], triangular fuzzy numbers (TFN) are the most popular means of judgement representation used in the research.

\subsection{MICMAC Analysis}

Basically, the MICMAC method is composed of the following steps [52]:

Step 1: Identify the variables. The variables can be identified by literature review, expert opinion, or brainstorming.

Step 2: Construct the structural analysis matrix. The group of experts provide an integer matrix M. Every cell $\mathrm{a}_{i j}$ of matrix M represents how variable $i$ influences variable $j$. For each pair of variables $i$ and $j$, the following question should be answered: Does factor $i$ have a direct influence on factor $j$ ? If yes, is the influence small, medium, high, or potential? The answer is [52]:

- $\quad 0$ if there is no influence between $i$ and $j$.

- 1 if there is a weak influence between $i$ and $j$.

- $\quad 2$ if there is a strong influence between $i$ and $j$.

- $\quad 3$ if there is a very strong influence between $i$ and $j$.

- $\quad$ P if there is a potential influence between $i$ and $j$.

All diagonal cells $\mathrm{a}_{i j}$ are equal to 0 .

Step 3: Analyze the direct influence. The direct analysis evaluates the overall direct influence $D I_{i}$ and direct dependence $D P_{i}$ of a variable in the system directly from the direct matrix. The influence (driving power), $D I_{i}$, and dependence power, $D P_{i}$, are determined by the following formula:

$$
\begin{aligned}
& D I_{i}=\sum_{j=1}^{n} \mathrm{a}_{i j}(i=1,2,3 \ldots, n) \\
& D P_{i}=\sum_{j=1}^{n} \mathrm{a}_{j i}(i=1,2,3 \ldots, n)
\end{aligned}
$$

Step 4: Analyze the indirect influence. Indirect analysis evaluates the overall influence and dependence of a variable through other variables. Indirect classification is obtained after increasing the matrix power $M$ (matrix multiplication $M^{2}=M \times M, M^{3}=M \times M$ $\times \mathrm{M}$, etc.) [52]. Algorithms used in MICMAC analyze the spread of interactions in the 
system through the connections and feedback loops linking individual factors. This allows prioritizing them based on the number of lap settings and a loop length of $1,2, \ldots, n$, coming in and out of each factor. As a result, the hidden influences, which are difficult for experts to define directly, are revealed. Usually, the classification is stable after 3,4 , or 5 degrees of multiplication [52].

Step 5: Assign the variables to the clusters. The MICMAC analysis classifies variables into four clusters based on their driving power $D I_{i}$ and dependence power $D P_{i}$ [38]. Cluster I consists of "Autonomous factors", which have a weak driving power $D I_{i}$ and a weak dependence power $D P_{i}$. This means that the factor is relatively disconnected from the system. Cluster II consists of "Dependence factors", which have a strong $D I_{i}$ and a weak $D P_{i}$. This means the factor is primarily dependent on other factors. Cluster III consists of "Linkage factors", which have a strong $D I_{i}$ as well as a strong $D P_{i}$. The connecting factors are unstable and most influence for other. Cluster IV consists of "Independent/Driving factors" that have a strong $D I_{i}$ but a weak $D P_{i}$. These factors are the most important.

\subsection{Fuzzy AHP}

The procedure of building an F-AHP model follows establishing the comparison matrix, aggregating multiple judgements, measuring the consistency, and defuzzfying the fuzzy weights as follows [47,51]:

Step 1: Identify the relevant criteria. The assessment criteria can be identified with the opinion of experts, brainstorming, or literature review.

Step 2: Establish the fuzzy pairwise comparison matrix. It is a fundamental step of building an F-AHP model to establish the pairwise comparison matrix with the expert's judgement. Linguistic terms describe the relative importance of one criterion over another. The mapping between the linguistic term and the fuzzy set must conform to a scale so that the same judgement is produced. A triangular fuzzy number is the most popular means of judgement representation. TFN is usually represented by three letters: $1, \mathrm{~m}$, and $\mathrm{u}$. These parameters, respectively, represent the minimum possible value, the median value, and the maximum possible value (i.e., $1<\mathrm{m}<\mathrm{u}$ ) [50]. A fuzzy scale defined by a series of fuzzy sets depicts the levels of linguistic terms, which links the verbal and numerical expressions. According to [49], the commonly used fuzzy scales are the 5- and 9-level.

Step 3: Defuzzify each triangular fuzzy number in the pairwise comparison matrix and calculate the consistency index. Using M Crisp $(1+4 m+u) / 6$, each triangular fuzzy number, $\mathrm{M}=(\mathrm{l}, \mathrm{m}, \mathrm{u})$ is converted to a crisp number. After that, the consistency of the matrix is checked by the method in crisp AHP $[45,46]$. The consistency index for a matrix is calculated according to equation:

$$
C I=\frac{\left(\lambda_{\max }-n\right)}{(n-1)}
$$

where $\left(\lambda_{\max }\right)$ is the principal eigenvalue of the judgement matrix, and $n$ is the order of the judgement matrix. If the $\lambda_{\max }$ is closer to $n$, the more consistent the judgments are. The difference $\lambda_{\max }-n$ is a measure of inconsistency (i.e., the perfect consistency refers to the zero difference) [39]. To derive an appreciated interpretation of the CI index, different sizes of matrices were developed. The calculation is performed by calculating $\mathrm{CI}_{\mathrm{S}}$ and $\mathrm{CI}$ for each size of the matrix (i.e., referred to as an RCI—random consistency index) [39].

The consistency ratio (CR) is defined according to the equation:

$$
C R=\frac{C I}{R C I}
$$

where if $C R<0.1$ (or 10\%), then the judgments are considered consistent. 
Step 4: Calculate the value of the fuzzy synthetic extent values. The fuzzy synthetic extent value of the criteria is defined as:

$$
S_{i}=\sum_{j=1}^{m} M_{g i}^{j} \otimes\left[\sum_{i=1}^{n} \sum_{j=1}^{m} M_{g i}^{j}\right]^{-1}
$$

where $M_{g i}^{j}(j=1,2,3, \ldots, n)$ are TFNs.

Step 5: Compute the degree of possibility of $M_{i} \geq M_{j} V\left(S_{i} \geq S_{j}\right)$ according to the equation:

$$
S_{i} \geq S_{j} V\left(S_{i} \geq S_{j}\right)=\left\{\begin{array}{c}
1, \text { if } m_{i} \geq m_{j} \\
\left.\frac{u_{i}-u_{j}}{\left(u_{i}-m_{i}\right)+\left(m_{j}-l_{j}\right)}, \text { if } l_{j} \leq u_{i}, i, j=1, \ldots, n ; i \neq j\right) \\
0, \text { others }
\end{array}\right\}
$$

Step 6: Calculate the degree of possibility of $S_{i}$ over all fuzzy numbers. The degree of possibility of $S_{i}$ is defined as:

$$
V\left(S_{i} \geq S_{j} I j=1, \ldots, n ; i \neq j\right)=\min V\left(S_{i} \geq S_{j}\right), j \epsilon(1, \ldots, n), i=1, i \neq j
$$

Step 7: Define the priority vector $\mathrm{W}=\left(\mathrm{w}_{i}, \ldots, \mathrm{w}_{n}\right)^{\mathrm{T}}$ of the fuzzy comparison matrix for a convex fuzzy number to be larger than $k$ convex fuzzy numbers

$$
w_{i}=\frac{V\left(S_{i} \geq S_{j}, j \epsilon(1, \ldots, n), i=1, i \neq j\right)}{\sum_{k=1}^{n}\left(S_{k} \geq S_{j} I j=1, \ldots, n ; j \neq k\right)}
$$

where $\mathrm{W}$ is a non- fuzzy number. It gives the priority weights of each criterion.

\subsection{Fuzzy TOPSIS}

The procedure of fuzzy TOPSIS used in this study is similar to the approach used by Chen [53] and can be expressed in six steps:

Step 1: Choose the appropriate linguistic variables for the linguistic ratings for alternatives with respect to criteria. Linguistic variables can be expressed in triangular fuzzy numbers (TFN), as in Table 1 as presented in [53].

Table 1. Linguistic expression for alternative ratings. Source: Own table adapted from [53].

\begin{tabular}{ccc}
\hline Linguistic Expression & Abbreviation & Triangular Fuzzy Number \\
\hline Very poor & VP & $(0,0,1)$ \\
Poor & P & $(0,1,3)$ \\
Medium poor & MP & $(1,3,5)$ \\
Fair & F & $(3,5,7)$ \\
Medium good & MG & $(5,7,9)$ \\
Good & G & $(7,9,10)$ \\
Very good & VG & $(9,10,10)$ \\
\hline
\end{tabular}

Decision-makers use the linguistic variables (shown as Table 1) for the rating of alternatives with respect to many criteria.

Assume that a decision group has $\mathrm{K}$ persons, then the rating of alternatives with respect to each criterion can be calculated as [53]:

$$
\widetilde{x}_{i j}=\left[\widetilde{x}_{i j}^{1}(+) \widetilde{x}_{i j}^{2}(+) \ldots(+) \widetilde{x}_{i j}^{K} / K\right]
$$

where $\widetilde{x}_{i j}^{K}$ is the rating of the $K$ th decision-maker.

Step 2: Determine decision matrix $D_{i}$ of $i$ th decision-maker and compute the fuzzy decision matrix. 
There are $K$ decision-makers $\left(D=\left(D_{1}, D_{2}, \ldots, D_{k}\right)\right)$, $n$ alternatives $\left(A=\left(A_{1}, A_{2}, \ldots\right.\right.$, $\left.A_{n}\right)$ ), and $m$ criteria $\left(C_{1}, C_{2}, \ldots, C_{m}\right)$. The performances of alternatives under $j$ criteria are obtained by each decision-maker with linguistic values based on Table 1 . Then, based on the aggregated assessments of alternatives, a fuzzy decision matrix is constructed [53]:

$$
\widetilde{\boldsymbol{D}}=\left[\widetilde{x}_{i j}\right]_{m \times n^{\prime}} i=1,2, \ldots, m, j=1,2, \ldots, n,
$$

where $\widetilde{x}_{i j}, \forall i, j$ are linguistic variables, $\widetilde{x}_{i j}=\left(a_{i j}, b_{i j}, c_{i j}\right)$.

Step 3: Normalize the fuzzy decision matrix and compute the weighted normalized matrix.

The raw data are normalized using a linear scale transformation to bring the various criteria scales into a comparable scale. The normalized fuzzy decision matrix $\widetilde{\boldsymbol{R}}$ is given by [53]:

$$
\widetilde{\boldsymbol{R}}=\left[\widetilde{r}_{i j}\right]_{m \times n^{\prime}} i=1,2, \ldots, m, j=1,2, \ldots, n
$$

where

$$
\begin{aligned}
& \widetilde{r}_{i j}=\left(\frac{a_{i j}}{c_{j}^{*}}, \frac{b_{i j}}{c_{j}^{*}}, \frac{c_{i j}}{c_{j}^{*}}\right), c_{j}^{*}=\max _{i} c_{i j} j \in B, \quad \text { (benefit criteria) } \\
& \widetilde{r}_{i j}=\left(\frac{a_{j}^{-}}{c_{i j}}, \frac{a_{j}^{-}}{b_{i j}}, \frac{a_{j}^{-}}{a_{i j}}\right), a_{j}^{-}=\min _{i} a_{i j} j \in C, \text { (cost criteria) }
\end{aligned}
$$

The normalization method mentioned above is to preserve the property that the ranges of normalized triangular fuzzy numbers belong to [0; 1 .

Considering the different importance of each criterion, the weighted normalized fuzzy decision matrix can be constructed as [53]:

$$
\widetilde{V}=\left[\widetilde{v}_{i j}\right]_{m \times n^{\prime}} i=1,2, \ldots, m, j=1,2, \ldots, n,
$$

where $\widetilde{\mathrm{v}}_{i j}=\widetilde{r}_{i j}(0) \widetilde{w}_{j}$.

Step 4: Determine the fuzzy positive ideal solution (FPIS) and fuzzy negative ideal solution (FNIS) and compute the distance of each alternative from the FPIS and FNIS.

Compute the fuzzy positive ideal solution (FPIS) and fuzzy negative ideal solutions (FNIS):

$$
\begin{aligned}
A^{*} & =\left(\widetilde{v}_{1}^{*}, \widetilde{v}_{2}^{*}, \ldots, \widetilde{v}_{n}^{*}\right) \\
A^{-} & =\left(\widetilde{v}_{1}^{-}, \widetilde{v}_{2}^{-}, \ldots, \widetilde{v}_{n}^{-}\right)
\end{aligned}
$$

where $\widetilde{v}_{j}^{*}=(1,1,1)$, and $\widetilde{v}_{j}^{-}=(0,0,0), j=1,2, \ldots, n$.

The distance of each alternative from $A^{*}$ and $A^{-}$can be calculated as:

$$
\begin{aligned}
& d_{i}^{*}=\sum_{j=1}^{n} d\left(\widetilde{v}_{i j}, \widetilde{v}_{j}^{*}\right), i=1,2, \ldots, m, \\
& d_{i}^{-}=\sum_{j=1}^{n} d\left(\widetilde{v}_{i j}, \widetilde{v}_{j}^{-}\right), i=1,2, \ldots, m,
\end{aligned}
$$

where $\mathrm{d}(\cdot, \cdot)$ is the distance measurement between two fuzzy numbers.

Step 5: Compute the closeness coefficient $\left(C C_{i}\right)$ of each alternative. A closeness coefficient is defined to determine the ranking order of all alternatives once the $d_{i}^{*}$ and $d_{i}^{-}$ of each alternative $A_{i}(i=1,2, \ldots, \mathrm{m})$ has been calculated. The closeness coefficient $\left(C C_{i}\right)$ of each alternative is calculated as the following formula:

$$
C C_{i}=\frac{d_{i}^{-}}{d_{i}^{*}+d_{i}^{-}}, i=1,2, \ldots, m
$$


Step 6: Rank the alternatives. According to the closeness coefficient, the ranking order of all alternatives can be determined, and the best one from among a set of feasible alternatives can be selected. The best alternative is closest to the FPIS and farthest from the FNIS.

\section{Results and Analysis}

The proposed framework for identification and evaluation of the maintenance factors affecting sustainability issues in manufacturing processes was performed in the manufacturing company according to the methodology presented in Figure 2 and Algorithm 1 . The structure of Algorithm 1 was prepared as suggested in [54].

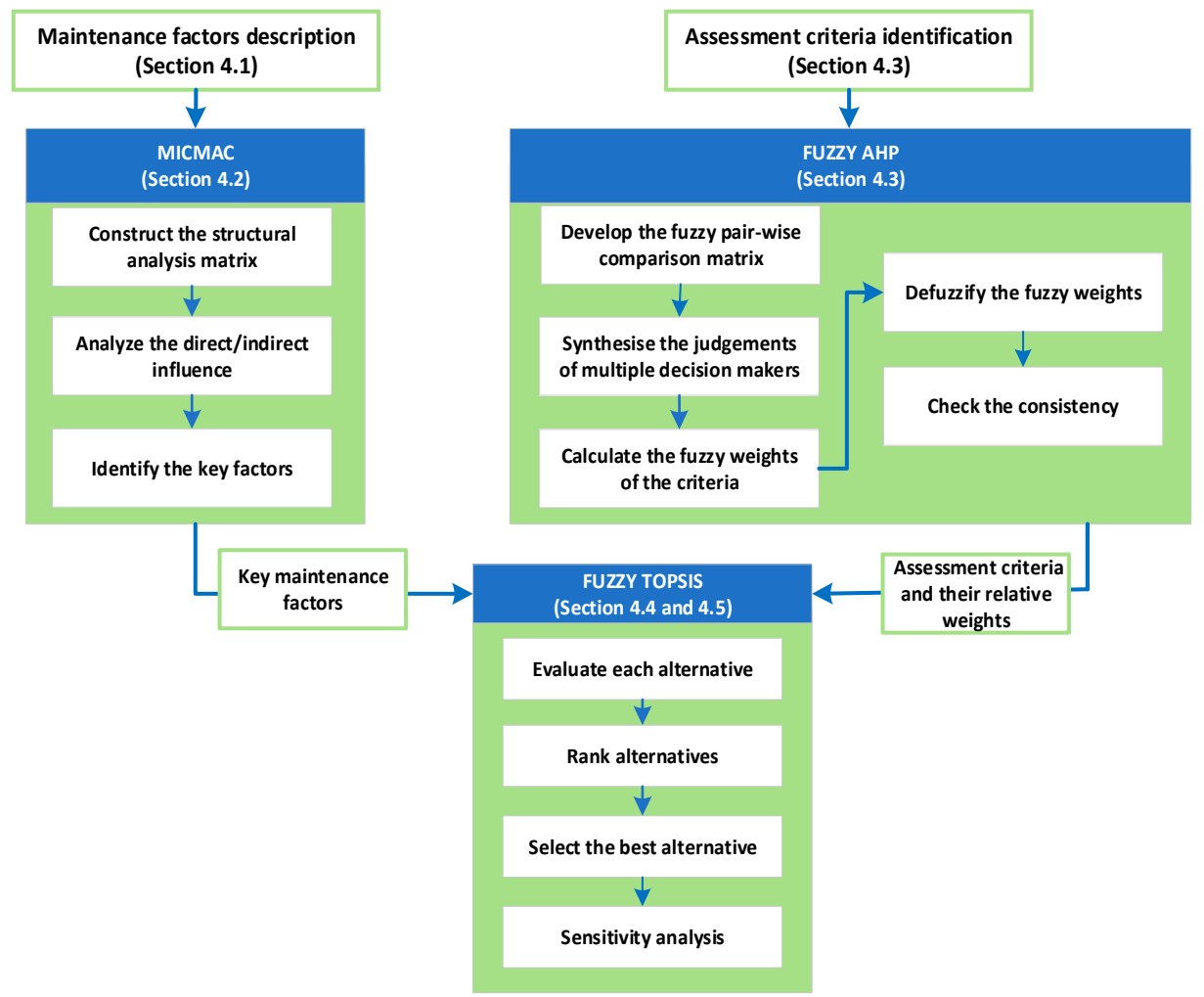

Figure 2. The model of the research.

\subsection{Description of Maintenance Factors Affecting Sustainable Manufacturing}

According to the research methodology presented in Figure 2, the first stage of the study presents the maintenance factors affecting the sustainable manufacturing from a tactical point of view. The list of these factors includes 10 items, according to [14] and are presented in more detail below.

$A_{1}$ Spare parts and consumables management. The management of spare parts and consumables is one of the key elements that support effective planning and scheduling of work and ensures their quality and efficiency. In enterprises, optimization concerns the minimalization of storage costs, the reduction of the probability of missing parts, machines inventory with hardware criticality, forecasting needs, stock levels, and the management of substitutes [55-59].

$A_{2}$ Cooperation with manufacturers/suppliers of machinery. Enterprises more and more often expect manufacturers and suppliers of machines to actively participate in the process of planning new investments as well as in the processes of using and servicing the purchased machines and devices. New technologies of Industry 4.0 enable machine manufacturers to obtain comprehensive information from their customers (machine users). This information makes it possible to present the potential opportunities and threats associ- 
ated with a new investment and better adaptation to current and past customers' needs. Moreover, by monitoring the machine usage (digital technologies allow the possibility of access to more information and the collection and processing of data), manufacturers can obtain information that allows their customers use the equipment more efficiently (often in real time), and thus they can identify and eliminate the wastes in the implemented processes. Therefore, maintenance collaboration with manufacturers and suppliers of production equipment is essential. [60-63].

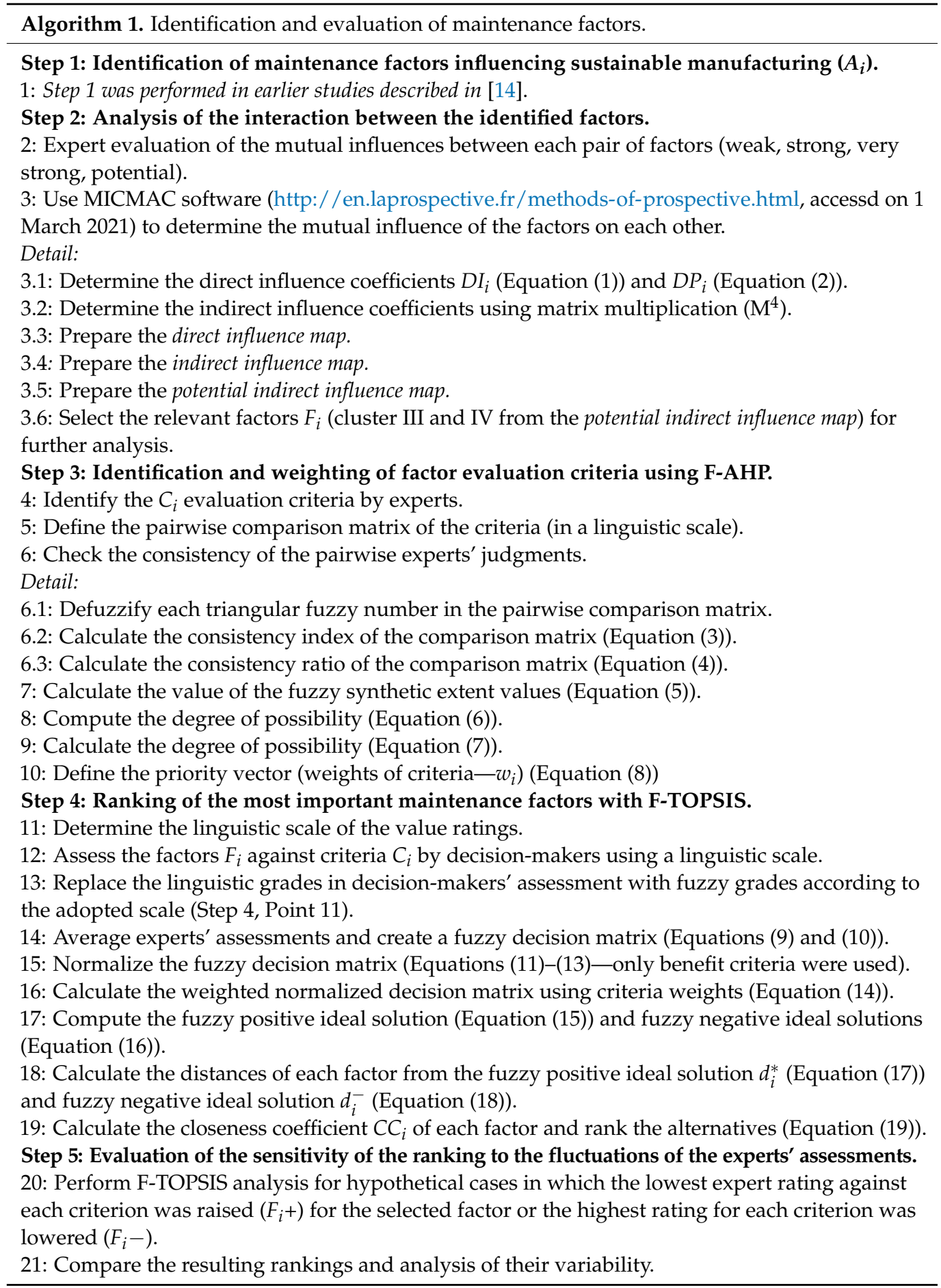

$A_{3}$ Cooperation with service providers. The service provider is a crucial part in the maintenance processes realization [64]. According to [65], in a circular economy, maintenance providers must consider environmental compatibility, energy efficiency, and 
human health and safety. As such, the selection of appropriate service providers is critical. The problem of service provider selection in maintenance service was discussed by [66]. The need for cooperation with service providers is pointed out by $[67,68]$.

$A_{4}$ Cooperation of maintenance with the research and development (R\&D) department. Collaboration between $R \& D$ and maintenance departments concerns all issues related to sustainable development. At the stage of designing a new product, it is necessary to take into account not only the requirements of the user (machine operator), but also the requirements of the employees who carry out the maintenance processes of the machines [69,70]. Moreover, when introducing a new product for production, it is necessary to establish the required machine working parameters and the necessary tools and machine equipment [71]. The consequence of good cooperation between these departments is products in accordance with the specification that are user-friendly and maintenance-friendly.

$A_{5}$ Cooperation with production and quality (P\&Q) departments. Production and maintenance are three functionally related departments in the manufacturing enterprise. Understanding the interactions and trade-offs between these departments is essential for rationale decision-making [72-77]. According to [78], "the three-way integration of production, maintenance, and quality, all major functions in the production system can be optimized simultaneously, resulting in a global optimal solution". That is why appreciating the cooperation between maintenance and P\&Q departments is important.

$A_{6}$ Cooperation with the safety, health, and environment (SHE) department. According to the results of the research conducted by Hill and Seabrook [79], 71\% of the respondents believe that SHE is a department in organizations that fits well with sustainability. Thus, SHE professionals can play an important part in achieving the sustainable aspirations of organizations. Safety is a priority in the whole maintenance system and should be part of the routine procedures [80].

Due to the risky nature of maintenance activity, SHE departments need to work together in the planning and supervision of working conditions, both for the company and for the maintenance operators. Both maintenance and SHE departments are secondary activities of companies, and both are seen as a necessary cost for proper operations [80]. Cooperation with the SHE department allows reduction in the risks in relation to people. Good cooperation also means building knowledge and awareness, complying with legal requirements, and helping in improving activities [10,64]. According to [81], effective communication related to maintenance tasks and communication amongst workers are the first step in achieving more safety in the working environment in repair and other maintenance activities

$A_{7}$ Competence of maintenance workers. Two factors-technology and people-are the keys to transforming maintenance processes, in a way enabling meeting requirements of sustainable manufacturing. The main factor that affects the quality of maintenance processes is competent employees [82,83]. Their knowledge and skills determine the efficiency of machines and devices in an enterprise [70]. This is especially important in relation to the new generation of manufacturing machines and challenges related to the Maintenance 4.0 technologies [84]. Regarding new technologies and digitalization of manufacturing processes, $[85,86]$ suggested that securing competencies and competence development is a long-term challenge for maintenance organizations.

$A_{8}$ Implementation of preventive and prognostic service strategies. Several maintenance strategies in the literature are proposed [87]. According to [30,88-90], an effective maintenance strategy may decrease environmental risks, energy usage and reduce greenhouse gas emissions, water pollution, soil contamination, and cost reduction. Regarding sustainability challenges, [23,91,92] believe that "predictive maintenance is one particular area, enabled by digital technologies, that has much to offer towards the effective utilisation of maintenance for sustainability". The application of preventive and prognostic maintenance strategies requires reliable data and information as well as systems for their processing and management $[86,93,94]$. 
$A_{9}$ The usage of maintenance and operation $(\mathrm{M} \& \mathrm{O})$ data collection and processing systems. Data are the key to maintenance process planning and realization. The use of data allows a better understanding of factors affecting the operation of machines and provides more opportunity to predict upcoming events. Owing to this, maintenance processes will be able to be carried out in a more predictive way than before. Real-time data acquisition enables the development of a joint control framework for maintenance and energy saving to reduce energy waste and improve system efficiency [95]. By utilizing oil analysis data to implement optimal maintenance, it is possible to ensure operation safety, availability, and environmental and economic gains [96]. According to [97], data analytics "enabling companies to implement safety programmes focused on zero fatalities (rather than zero harm). Companies are able to better correlate the safety data they collect with other available data-sets (e.g., production data, employee rosters, maintenance schedules, etc.). By correlating this data, companies can recognize safety incident patterns and employees that are particularly at risk. They are then in the position to adopt processes and procedures to minimize incidents and injuries".

$A_{10}$ Modernization of machines and devices. An alternative to buying new machines is changing the implementation of the existing machines. These changes allow one to adopt machines according to the current needs: performance and a production profile of the company. The modernization of industrial machines is often related to the programming and assembly of industrial automation systems. Additionally, the implemented changes improve the efficiency of technological processes, the efficiency of raw materials usage, and the consumption of technological media (water, compressed air, energy). Moreover, the modernization of machines and equipment improves the working conditions of operators, especially the safety of performed activities. In addition, the modernization of the machinery can reduce the risk of unexpected failures, and thus decrease repair costs. Owing to modernization, many years of equipment and machinery can be adapted to the requirements of a modern plant $[10,20,70,98]$.

Table 2 shows the 10 maintenance factors affecting sustainable manufacturing.

Table 2. Maintenance factors affecting sustainable manufacturing.

\begin{tabular}{clc}
\hline No. & \multicolumn{1}{c}{ Factor } & References \\
\hline$A_{1}$ & Spare parts and consumables management & {$[10,27,55,56,58,59,86,99-101]$} \\
$A_{2}$ & Cooperation with manufacturers/suppliers of machinery & {$[9,10,60,65,66,86,102,103]$} \\
$A_{3}$ & Cooperation with service providers & {$[9,10,64,67,68]$} \\
$A_{4}$ & Cooperation with R\&D department & {$[10,69,104]$} \\
$A_{5}$ & Cooperation with P\&Q departments & {$[9,10,69,72,75-77,86,104-113]$} \\
$A_{6}$ & Cooperation with SHE department & {$[9,10,64,80,81,86,102,110,114-119]$} \\
$A_{7}$ & Competence of maintenance workers & {$[9,10,70,82,84-86,110,120,121]$} \\
$A_{8}$ & Implementation of preventive and prognostic service strategies & {$[10,71,85,86,100,102,122-125]$} \\
$A_{9}$ & The usage of M\&O data collection and processing systems & {$[57,85,86,97,126-128]$} \\
$A_{10}$ & Modernization of machines and devices & {$[10,20,97,98,102]$} \\
\hline
\end{tabular}

The ten factors presented above ( $A_{1}$ to $\left.A_{10}\right)$ specify that by improving the effectiveness of the maintenance processes, companies could create conditions for supporting the implementation of sustainable manufacturing challenges.

\subsection{Clustering and Identification of Key Maintenance Factors Affecting Sustainable Manufacturing (MICMAC)}

MICMAC analysis was performed for 10 factors, according to Table 2. For the factors, a structural analysis matrix $(\mathrm{M})$ was constructed. The impact of the factors was assessed together by a team from the company:

- The first team (D1) represented production and consisted of a production manager and a foreman; 
- The second team (D2) represented the maintenance department and consisted of a maintenance manager and a maintenance technician;

- The third team represented SHE and consisted of two people: an occupational health and safety specialist and an environmental management specialist.

The representatives were asked to assess the degree of influence between each pair of factors on a 4-level scale from 0 , no influence; 1 , low influence; 2 , medium influence; and 3, high influence and P (potential influence-grey shade in the Table 3). In each case, representatives were asked if the change to the first factor (listed in a row) would cause a direct change to the second factor (listed in a column). Each factor with respect to the rest of the factors was evaluated (Table 3).

Table 3. The degree of influence between each pair of factors.

\begin{tabular}{ccccccccccc}
\hline & $\boldsymbol{A}_{\mathbf{1}}$ & $\boldsymbol{A}_{\mathbf{2}}$ & $\boldsymbol{A}_{\mathbf{3}}$ & $\boldsymbol{A}_{\mathbf{4}}$ & $\boldsymbol{A}_{\mathbf{5}}$ & $\boldsymbol{A}_{\mathbf{6}}$ & $A_{\mathbf{7}}$ & $\boldsymbol{A}_{\mathbf{8}}$ & $\boldsymbol{A}_{\mathbf{9}}$ & $A_{\mathbf{1 0}}$ \\
\hline $\boldsymbol{A}_{1}$ & 0 & 0 & 0 & 0 & 2 & 0 & 0 & 0 & 0 & 0 \\
$\boldsymbol{A}_{2}$ & 1 & 0 & 1 & 0 & 1 & 1 & 2 & 1 & 1 & 1 \\
$A_{3}$ & 2 & 0 & 0 & 0 & 3 & 0 & 1 & 1 & 0 & 1 \\
$A_{4}$ & 1 & 1 & 1 & 0 & 2 & 2 & 1 & 0 & 0 & 2 \\
$A_{5}$ & 0 & 3 & 2 & $\mathrm{P}$ & 0 & 0 & 2 & 0 & 3 & 3 \\
$A_{6}$ & 3 & 2 & 3 & 0 & 3 & 0 & 2 & 1 & 0 & 2 \\
$A_{7}$ & 0 & 0 & 0 & 0 & 2 & 0 & 0 & 3 & 0 & 2 \\
$A_{8}$ & 3 & 3 & 3 & 0 & 3 & 0 & 2 & 0 & 3 & 2 \\
$A_{9}$ & 3 & 2 & 3 & 0 & 3 & 2 & 1 & 3 & 0 & 1 \\
$A_{10}$ & 3 & $\mathrm{P}$ & 1 & 0 & 1 & 0 & $\mathrm{P}$ & 2 & 1 & 0 \\
\hline
\end{tabular}

The size of the matrix was $10 \times 10$, which means that the experts participating in the study were asked to determine relationships between the variables. In 41 cases, the dominant value was zero, which means no influence between the factors; in 20 cases, weak influences were found; and in 18 cases, a medium influence was found. Strong influences between the factors were found in 18 cases, while the potential influence was identified only in three cases.

First, the direct influence $D I_{i}$ and the dependence power $D P_{i}$ between 10 maintenance factors affecting the sustainable production were analayzed. In Table 4 , the calculated direct influence $D I_{i}$ and the dependence $D P_{i}$ between factors are presented.

Table 4. The influence and the dependence between factors.

\begin{tabular}{ccc}
\hline No. & $\boldsymbol{D I}_{\boldsymbol{i}}$ & $\boldsymbol{D} \boldsymbol{P}_{\boldsymbol{i}}$ \\
\hline $\boldsymbol{A}_{1}$ & 2 & 16 \\
$\boldsymbol{A}_{2}$ & 9 & 11 \\
$\boldsymbol{A}_{3}$ & 8 & 14 \\
$\boldsymbol{A}_{4}$ & 10 & 0 \\
$\boldsymbol{A}_{5}$ & 13 & 20 \\
$\boldsymbol{A}_{6}$ & 16 & 5 \\
$\boldsymbol{A}_{7}$ & 7 & 11 \\
$\boldsymbol{A}_{8}$ & 19 & 11 \\
$\boldsymbol{A}_{9}$ & 18 & 8 \\
$\boldsymbol{A}_{10}$ & 8 & 14 \\
& 110 & 110 \\
& The highest values & \\
\hline
\end{tabular}

The obtained results indicate that the highest direct influence is gained by factors $A_{8}$, $A_{9}, A_{6}$, and $A_{5}$ with the influence values $D I_{i}=19,18,16$, and 13 , respectively. The lowest influence $D I_{i}$ was identified for factors $A_{1}=2$. However, the most dependent factors are $A_{5}$ $\left(D P_{i}=20\right), A_{3}$, and $A_{10}\left(D P_{i}=14\right)$, as well as $A_{1}\left(D P_{i}=16\right)$. No dependence was identified for the factor $\mathrm{A}_{4}\left(D P_{i}=0\right)$. Additionally, as part of the analysis, a direct graph presenting 
the direct influences of the factors was created (Figure 2). MICMAC software was used (http:/ / en.laprospective.fr/methods-of-prospective.html, accessed on 1 March 2021) to perform the analyses.

The analysis of the graph presented in Figure 3 shows that the factors $A_{5}$ and $A_{1}$ have the strongest influences on other factors. This factor has a strong influence from the factors $A_{2}$ and $A_{9}$. The factor $A_{1}$ has the strongest influence from factors: $A_{6}, A_{9}$, $A_{8}$, and $A_{10}$. Moreover, a map that classifies factors based on $D I_{i}$ and $D P_{i}$ was created. MICMAC analysis was used to classify 10 factors into four clusters based on their $D I_{i}$ and $D P_{i}$ (Figure 4).

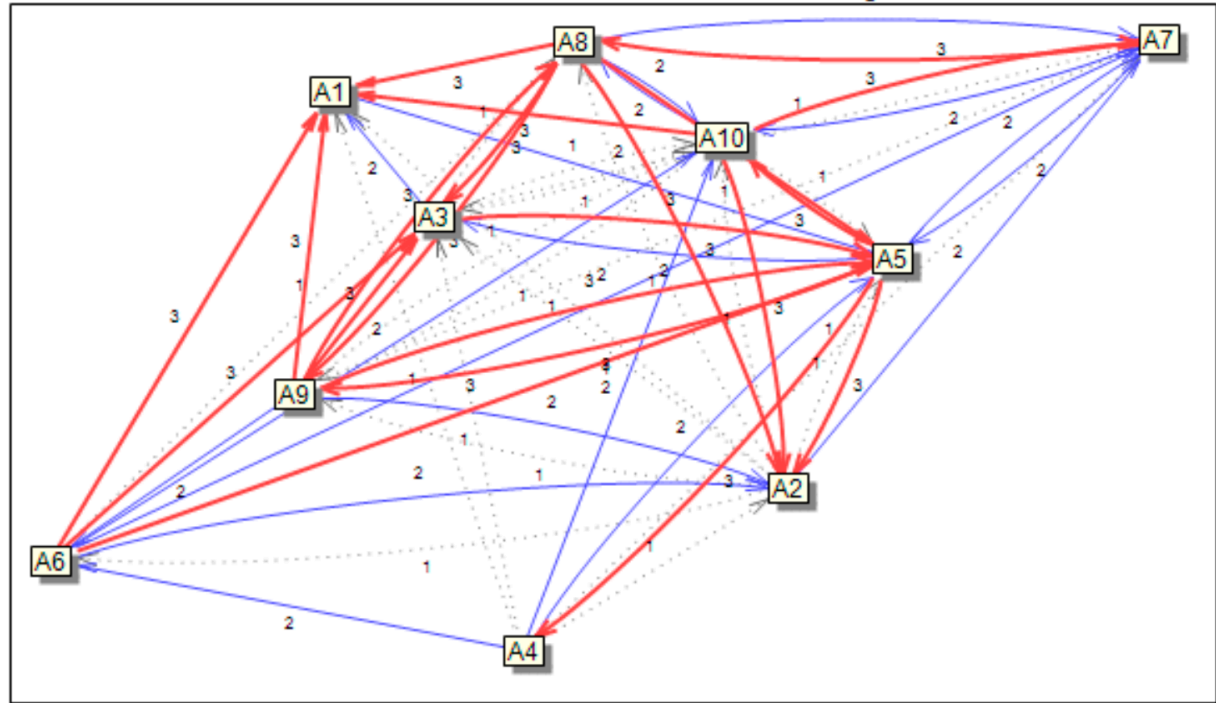

Weakest influences

Weak influences

- Moderate influences

- Relatively strong influences

- Strongest influences

Figure 3. Direct influence graph.

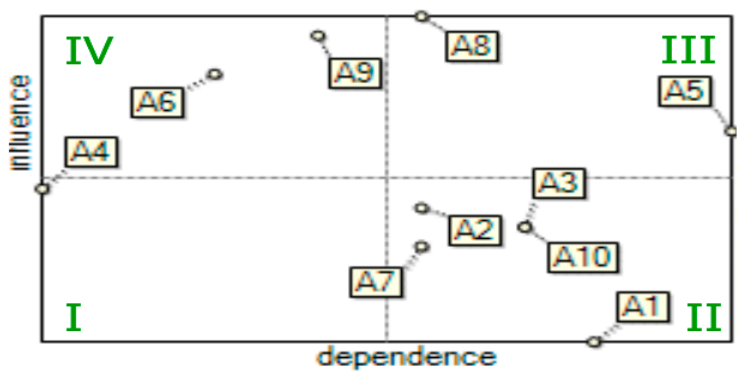

Figure 4. Direct influence/dependence map.

Cluster I consists of "Autonomous factors". In this case, factor $A_{4}$ belongs to Cluster I, which means that this factor is relatively disconnected from the system. Cluster II consists of "Dependence factors". In this case, they are: $A_{1}, A_{2}, A_{3}, A_{7}$, and $A_{10}$. Cluster III consists of "Linkage factors". In this case, they are the $A_{5}$ and $A_{8}$ factors. The factor $A_{5}$ has the strongest dependence value, which means it is the most direct maintenance factor affecting sustainable manufacturing. Cluster IV consists of "Independent/Driving factors": factors $A_{6}$ and $A_{9}$. These factors are the maintenance factors which the most affecting sustainable manufacturing and are the key factors that fall into the linkage or independent factor cluster.

In the next step, indirect impacts were taken into account. To determine the matrix of indirect influence (Table 5), the matrix of direct influence was used as the input data. 
Table 5. The matrix of indirect influence.

\begin{tabular}{ccccccccccc}
\hline & $\boldsymbol{A}_{\mathbf{1}}$ & $\boldsymbol{A}_{\mathbf{2}}$ & $\boldsymbol{A}_{\mathbf{3}}$ & $\boldsymbol{A}_{\mathbf{4}}$ & $\boldsymbol{A}_{\mathbf{5}}$ & $\boldsymbol{A}_{\mathbf{6}}$ & $\boldsymbol{A}_{\mathbf{7}}$ & $\boldsymbol{A}_{\mathbf{8}}$ & $\boldsymbol{A}_{\mathbf{9}}$ & $\boldsymbol{A}_{\mathbf{1 0}}$ \\
\hline $\boldsymbol{A}_{\mathbf{1}}$ & 4058 & 2934 & 3550 & 0 & 5056 & 1050 & 2980 & 3504 & 2932 & 3742 \\
$\boldsymbol{A}_{\mathbf{2}}$ & 15,422 & 11,900 & 13,854 & 0 & 19,138 & 3154 & 11,276 & 11,630 & 11,517 & 14,131 \\
$\boldsymbol{A}_{\mathbf{3}}$ & 12,299 & 9287 & 10,947 & 0 & 15,350 & 2772 & 9043 & 9837 & 9116 & 11,369 \\
$\boldsymbol{A}_{\mathbf{4}}$ & 15,328 & 11,534 & 13,616 & 0 & 19,004 & 3330 & 11,121 & 11,912 & 11,189 & 13,906 \\
$\boldsymbol{A}_{5}$ & 21,859 & 16,822 & 19,623 & 0 & 26,930 & 4399 & 15,785 & 16,377 & 16,178 & 19,826 \\
$\boldsymbol{A}_{6}$ & 21,890 & 16,808 & 19,626 & 0 & 27,373 & 4628 & 16,057 & 16,874 & 16,287 & 20,181 \\
$\boldsymbol{A}_{7}$ & 14,916 & 10,873 & 13,052 & 0 & 18,451 & 3496 & 10,744 & 12,171 & 10,705 & 13,465 \\
$\boldsymbol{A}_{8}$ & 29,062 & 22,364 & 26,090 & 0 & 36,064 & 6033 & 21,177 & 22,122 & 21,620 & 26,599 \\
$\boldsymbol{A}_{9}$ & 29,112 & 21,919 & 25,850 & 0 & 36,278 & 6367 & 21,166 & 22,704 & 21,298 & 26,480 \\
$\boldsymbol{A}_{10}$ & 12,792 & 9766 & 11,420 & 0 & 15,939 & 2693 & 9319 & 9789 & 9494 & 11,678 \\
\hline
\end{tabular}

The analysis of the indirect influence matrix shows a significant increase in the strength of interaction between the factors compared to the strength of direct interactions (large values of matrix elements). The degree of matrix filling has increased significantly from $59 \%$ in the case of the direct interaction matrix to $90 \%$ in the case of the indirect influence matrix. This indicates that taking into account indirect impacts significantly increases the network of relationships between factors. Currently, the column matrix with all zero elements corresponding to the factor $A_{4}$ indicates that this factor is independent. The calculation process of the indirect influence matrix achieved stability in relation to the ranking of the influence power and the dependence power of individual factors after four iterations $I=4$. In Table 6 , the calculated indirect influence and the dependence between selected factors are presented.

Table 6. The influence and dependence between factors (indirect impacts).

\begin{tabular}{ccc}
\hline No. & $\boldsymbol{D I}_{\boldsymbol{i}}$ & $\boldsymbol{D P}_{\boldsymbol{i}}$ \\
\hline $\boldsymbol{A}_{1}$ & 29,806 & 176,738 \\
$\boldsymbol{A}_{2}$ & 112,022 & 134,207 \\
$\boldsymbol{A}_{3}$ & 90,020 & 157,628 \\
$\boldsymbol{A}_{4}$ & 110,940 & 0 \\
$\boldsymbol{A}_{5}$ & 157,799 & 219,583 \\
$\boldsymbol{A}_{6}$ & 159,724 & 37,922 \\
$\boldsymbol{A}_{7}$ & 107,873 & 128,668 \\
$\boldsymbol{A}_{8}$ & 211,131 & 136,920 \\
$\boldsymbol{A}_{9}$ & 211,174 & 130,336 \\
$\boldsymbol{A}_{10}$ & 92,890 & 161,377 \\
& The highest values & \\
\hline
\end{tabular}

The results show that taking into account the indirect influences, the factors having the greatest impact on sustainable manufacturing did not change significantly. The highest influence $\left(D I_{i}\right)$ is still obtained by factors $A_{9}, A_{8}, A_{5}, A_{6}$, and the lowest influence $\left(D I_{i}\right)$ was identified for factor $A_{1}$. The sequence of the dependent factors has changed slightly, but they are still $A_{1}, A_{3}, A_{5}$, and $A_{9}$. No dependence was identified for the factor $A_{4}\left(D P_{i}=0\right)$ again. However, it should be noted that the assignment of factors to clusters has slightly changed (Figure 5).

Analyzing the results presented on the map, it should be noted that factor $A_{4}$ still belongs to Cluster I "Autonomous factors". In Cluster II "Dependence factors" are still $A_{1}$, $A_{2}, A_{3}, A_{7}$, and $A_{10}$. The changes are noticeable in clusters III and IV. Apart from factors $A_{5}$ and $A_{8}$, cluster III also includes factor $A_{9}$, which was previously assigned to cluster IV. Currently, cluster IV contains only one factor, $A_{6}$. Taking into account the indirect influences and dependence, this factor is the most impact maintenance factor affecting sustainable manufacturing. 


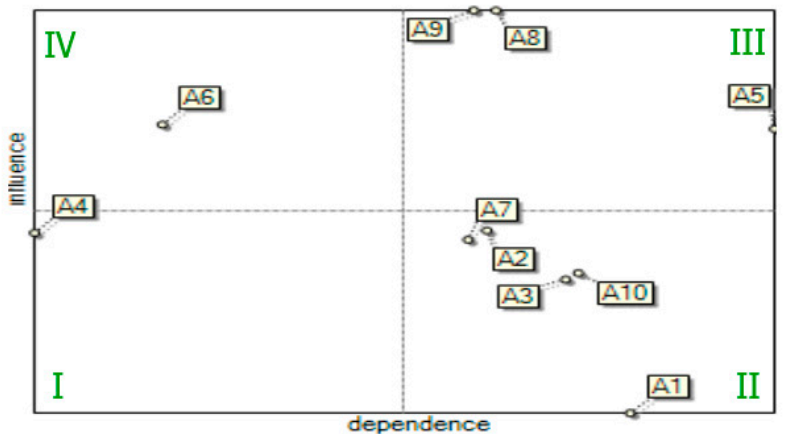

Figure 5. Indirect influence/dependence map.

The next step of the study was to determine the matrix of indirect impacts, taking into account the potential influence (Table 7).

Table 7. The matrix of indirect influences.

\begin{tabular}{ccccccccccc}
\hline & $\boldsymbol{A}_{\mathbf{1}}$ & $\boldsymbol{A}_{\mathbf{2}}$ & $\boldsymbol{A}_{\mathbf{3}}$ & $\boldsymbol{A}_{\mathbf{4}}$ & $\boldsymbol{A}_{\mathbf{5}}$ & $\boldsymbol{A}_{\mathbf{6}}$ & $\boldsymbol{A}_{\mathbf{7}}$ & $\boldsymbol{A}_{\mathbf{8}}$ & $\boldsymbol{A}_{\mathbf{9}}$ & $\boldsymbol{A}_{\mathbf{1 0}}$ \\
\hline $\boldsymbol{A}_{\mathbf{1}}$ & 5720 & 5754 & 5044 & 1998 & 7360 & 1734 & 5872 & 4914 & 4102 & 5644 \\
$\boldsymbol{A}_{\mathbf{2}}$ & 19,673 & 19,880 & 17,715 & 6606 & 25243 & 5137 & 19,931 & 15,710 & 14,295 & 19,429 \\
$\boldsymbol{A}_{\mathbf{3}}$ & 16,844 & 16,985 & 15,024 & 5793 & 21,710 & 4689 & 17,197 & 13,944 & 12,194 & 16,664 \\
$\boldsymbol{A}_{4}$ & 20,902 & 20,825 & 18,614 & 6885 & 26,876 & 5784 & 21,120 & 17,078 & 14,873 & 20,476 \\
$\boldsymbol{A}_{5}$ & 33,511 & 33,712 & 30,183 & 11,040 & 42,980 & 8977 & 33,800 & 26,871 & 24,110 & 33,008 \\
$\boldsymbol{A}_{6}$ & 29,234 & 29,456 & 26,232 & 9900 & 37,738 & 7793 & 29,686 & 23,768 & 21,177 & 28,938 \\
$\boldsymbol{A}_{7}$ & 20,058 & 19,846 & 17,660 & 6639 & 25,783 & 5911 & 20,344 & 16,854 & 14,056 & 19,555 \\
$\boldsymbol{A}_{\mathbf{8}}$ & 37,375 & 37,679 & 33,611 & 12,519 & 48,112 & 9984 & 37,866 & 30,177 & 27,050 & 36,967 \\
$\boldsymbol{A}_{9}$ & 36,936 & 36,994 & 32,978 & 12,345 & 47,519 & 10,018 & 37,429 & 30,159 & 26,452 & 36,311 \\
$\boldsymbol{A}_{10}$ & 25,893 & 26,344 & 23,435 & 8856 & 33,315 & 6665 & 26,305 & 20,727 & 18,971 & 25,745 \\
\hline
\end{tabular}

The analysis of the matrix shows that taking into account the potential interactions, the matrix was $100 \%$ fulfilled. In addition, it can be noticed that the relationships between the factors increased, which caused factor $A_{4}$ to be no longer completely independent. These changes are also noticeable in the summary results of the influence $D I_{i}$ and the dependence $D P_{i}$ between the analyzed factors (Table 8).

Table 8. The influence and dependence between factors (indirect).

\begin{tabular}{ccc}
\hline No. & \multicolumn{1}{c}{$\boldsymbol{D I}$} & $\boldsymbol{D I}_{\boldsymbol{i}}$ \\
\hline $\boldsymbol{A}_{1}$ & 48,142 & 246,146 \\
$\boldsymbol{A}_{2}$ & 163,619 & 247,475 \\
$\boldsymbol{A}_{3}$ & 141,044 & 220,496 \\
$\boldsymbol{A}_{4}$ & 173,433 & 82,581 \\
$\boldsymbol{A}_{5}$ & 278,192 & 316,636 \\
$\boldsymbol{A}_{6}$ & 243,922 & 66,692 \\
$\boldsymbol{A}_{7}$ & 166,706 & 249,550 \\
$\boldsymbol{A}_{8}$ & 311,340 & 200,202 \\
$\boldsymbol{A}_{9}$ & 307,141 & 177,280 \\
$\boldsymbol{A}_{10}$ & 216,256 & 242,737 \\
& The highest values & \\
\hline
\end{tabular}

The graph of potential indirect influences (Figure 6) indicates that only factor $A_{5}$ (cooperation with $\mathrm{P} \& \mathrm{Q}$ departments) is the factor with the strongest influence. This can be seen from the color change of the line that connects the factors. 


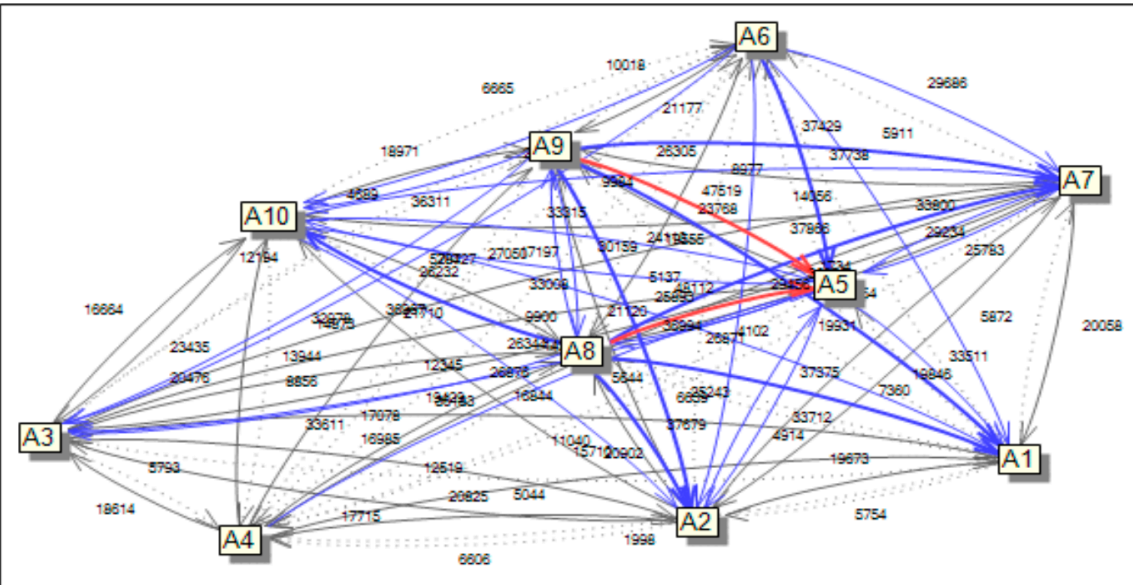

Weakest influences

Weak influences

Moderate influences

- Relatively strong influences

- Strongest influences

Figure 6. Potential indirect influence graph.

The changes are also noticeable on the potential indirect influence map (Figure 7). These changes are mainly related to cluster III and IV.

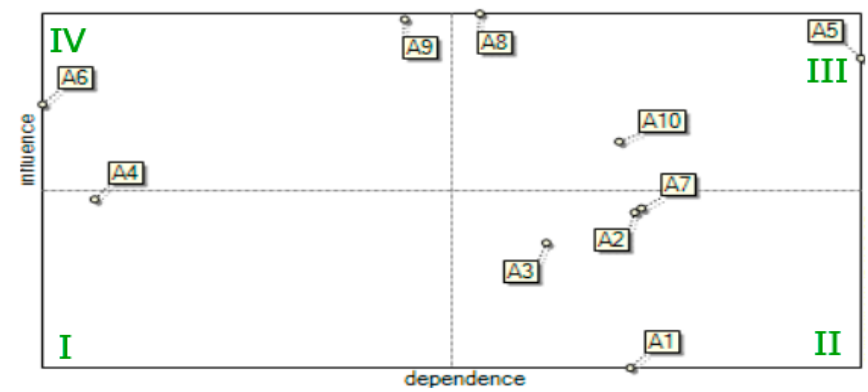

Figure 7. Potential indirect influence map.

Cluster III includes "Linkage factors" such as $A_{5}$ "Cooperation with P\&Q departments", $A_{8}$ "Implementation of preventive and prognostic service strategies", and $A_{10}$ "Modernization of machines and devices". Whereas, factors $A_{6}$ "Cooperation with the SHE department" and $A_{9}$ "The usage of $\mathrm{M} \& \mathrm{O}$ data collection and processing systems" in cluster IV were categorized as "Independent/Driving factors". Previously, factor $A_{9}$ was classified as cluster III.

To carry out further analysis, a team of experts chose factors from these clusters $\left(A_{5}\right.$, $A_{6}, A_{8}, A_{9}$, and $\left.A_{10}\right)$ as key maintenance factors affecting sustainable production. These factors were inputs for the F-TOPSIS analysis.

\subsection{Assessment Criteria Identification and Weighting (F-AHP)}

On the basis of the short-term and long-term goals set by the CEO and based on literature survey $[129,130]$ experts from the company defined the most important criteria according to which the assessment of maintenance factors influencing the implementation of sustainable challenges in the company will be carried out (Table 9). 
Table 9. The criteria for maintenance factor evaluation.

\begin{tabular}{lcc}
\hline No & Criteria \\
\hline$C_{1}$ & Manufacturing cost \\
$C_{2}$ & Energy consumption \\
$C_{3}$ & Waste reduction \\
$C_{4}$ & Operational safety \\
\hline
\end{tabular}

Firstly, the decision0maker teams from the company (D1-production team, D2maintenance team, D3-SHE team) constructed together the pairwise comparison matrix of the criteria. When analyzing the relationship between two factors, in each case of discrepancies the teams discussed and made decisions on the basis of consensus. In this study, a 5-level fuzzy scale according to [131] was adopted (Table 10).

Table 10. Linguistic expression for criteria ratings. Source: Own table adapted from [131].

\begin{tabular}{ccc}
\hline Linguistic Expression & Abbreviation & Triangular Fuzzy Number \\
\hline Extremely more importance & EMI & $(7 / 2,4,9 / 2)$ \\
Very strong importance & VSI & $(5 / 2,3,7 / 2)$ \\
Strong importance & SI & $(3 / 2,2,5 / 2)$ \\
Moderate importance & MI & $(2 / 3,1,3 / 2)$ \\
Equal importance & EI & $(1,1,1)$ \\
\hline
\end{tabular}

In Table 11, the fuzzy evaluation matrix using the triangular fuzzy numbers obtained by experts from the company scoring is presented.

Table 11. The fuzzy comparison matrix for the defined criteria.

\begin{tabular}{ccccc}
\hline Criteria & $\boldsymbol{C}_{\mathbf{1}}$ & $\boldsymbol{C}_{\mathbf{2}}$ & $\boldsymbol{C}_{\mathbf{3}}$ & $\boldsymbol{C}_{\mathbf{4}}$ \\
\hline$C_{1}$ & $(1,1,1)$ & $(2 / 3,1,3 / 2)$ & $(3 / 2,2,5 / 2)$ & $(1,1,1)$ \\
$C_{2}$ & $(3 / 2,1,2 / 3)$ & $(1,1,1)$ & $(2 / 3,1,3 / 2)$ & $(3 / 2,2,5 / 2)$ \\
$C_{3}$ & $(2 / 5,1 / 2,2 / 3)$ & $(3 / 2,1,2 / 3)$ & $(1,1,1)$ & $(2 / 3,1,3 / 2)$ \\
$C_{4}$ & $(1,1,1)$ & $(2 / 5,1 / 2,2 / 3)$ & $(3 / 2,1,2 / 3)$ & $(1,1,1)$ \\
\hline
\end{tabular}

After the pairwise comparison, the calculation method of consistency index and consistency ratio in crisp AHP for checking the consistency of the pairwise experts' judgments Equations (3) and (4) were used. In the analyzed case, $\lambda_{\max }=4.2339, C I=0.0780$, $C R=0.0866<0.1$, so the level of consistency ratio is acceptable.

To find the priority weights, the fuzzy synthetic extent values of the criteria by using Equation (5) were calculated. The different values of the fuzzy synthetic extent of the four different criteria are represented by $S_{1}, S_{2}, S_{3}, S_{4}$ (Table 12).

Table 12. Results of fuzzy analytic hierarchy process (F-AHP) analysis.

\begin{tabular}{|c|c|c|c|c|c|c|c|}
\hline & \multicolumn{3}{|c|}{ Fuzzy Synthetic Extent } & \multicolumn{2}{|c|}{$\mathbf{W}^{\prime}$} & \multirow{2}{*}{$\frac{\mathbf{W}}{0.3159}$} & \multirow{2}{*}{$\begin{array}{c}\text { Rank } \\
1\end{array}$} \\
\hline$S_{1}$ & 0.1953 & 0.2941 & 0.4348 & $C_{1}$ & 1.000 & & \\
\hline$S_{2}$ & 0.1797 & 0.2941 & 0.4710 & $C_{2}$ & 1.000 & 0.3159 & 1 \\
\hline$S_{3}$ & 0.1281 & 0.2059 & 0.3382 & $C_{3}$ & 0.6182 & 0.1953 & 2 \\
\hline$S_{4}$ & 0.1438 & 0.2059 & 0.3019 & $C_{4}$ & 0.5472 & 0.1729 & 3 \\
\hline
\end{tabular}

The degree of possibility and the minimum degree of possibility were determined by using Equations (6) and (7). Finally, the weights are given as $W^{\prime}$, and after normalization (Equation (8)) as $\mathrm{W}=(0.3159,0.3159,0.1953,0.1729)^{\mathrm{T}}$ (Table 12). The $\mathrm{R}$ software (version 3.6.1) was used to perform the analyses. 
Analyzing the results presented in Table 12, it should be noted that the most important criteria are $C_{1}$-manufacturing cost and $C_{2}$-energy consumption, then $C_{3}$-waste reduction, and finally $C_{4}$-operational safety.

\subsection{Ranking of the Most Important Maintenance Factors (F-TOPSIS)}

In this section, the five maintenance factors identified in Section 4.2 as key maintenance factors were ranked from the sustainability perspective using the four criteria obtained and weighted in Section 4.3. Firstly, each of the three decision-maker teams from the company (D1-production team, D2-maintenance team, D3-SHE team) used the linguistic rating variables (Table 13) were asked to rate each of the factors:

$F_{1}-\left(A_{5}\right)$ Cooperation with $\mathrm{P} \& \mathrm{Q}$ departments;

$F_{2}-\left(A_{6}\right)$ Cooperation with the SHE department;

$F_{3}-\left(A_{8}\right)$ Implementation of preventive and prognostic service strategies;

$F_{4}-\left(A_{9}\right)$ The usage of $\mathrm{M} \& \mathrm{O}$ data collection and processing systems;

$F_{5}-\left(A_{10}\right)$ Modernization of machines and devices;

with respect to each criterion (shown in Table 9).

Table 13. Linguistic rating variables. Source: [53].

\begin{tabular}{lc}
\hline \multicolumn{1}{c}{ Linguistic Terms } & TFN \\
\hline Very low important (VLI) & $(0,0,1)$ \\
Low important (LI) & $(0,1,3)$ \\
Medium low (ML) & $(1,3,5)$ \\
Medium Important (MI) & $(3,5,7)$ \\
Medium high (MH) & $(5,7,9)$ \\
High important (HI) & $(7,9,10)$ \\
Very important (VI) & $(9,10,10)$ \\
\hline
\end{tabular}

Then, the linguistic evaluation was converted into triangular fuzzy numbers (shown in Table 13) to construct the fuzzy decision matrix (Table 14).

Table 14. The ratings of the five factors by decision-makers under all criteria.

\begin{tabular}{lccccccc}
\hline & \multicolumn{2}{c}{ Linguistic Ratings } & & \multicolumn{3}{c}{ Fuzzy Ratings } \\
\hline $\boldsymbol{F} / \boldsymbol{C}$ & D1 & D2 & D3 & F/C & D1 & D2 & D3 \\
\hline $\boldsymbol{F}_{1} \cdot \boldsymbol{C}_{1}$ & $\mathrm{MI}$ & $\mathrm{MH}$ & $\mathrm{MH}$ & $\boldsymbol{F}_{1} \cdot \boldsymbol{C}_{1}$ & $(3,5,7)$ & $(5,7,9)$ & $(5,7,9)$ \\
$\boldsymbol{F}_{1} \cdot \boldsymbol{C}_{2}$ & $\mathrm{MI}$ & $\mathrm{MI}$ & $\mathrm{MI}$ & $\boldsymbol{F}_{1} \cdot \boldsymbol{C}_{2}$ & $(3,5,7)$ & $(3,5,7)$ & $(3,5,7)$ \\
$\boldsymbol{F}_{1} \cdot \boldsymbol{C}_{3}$ & $\mathrm{HI}$ & $\mathrm{MI}$ & $\mathrm{HI}$ & $\boldsymbol{F}_{1} \cdot \boldsymbol{C}_{3}$ & $(7,9,10)$ & $(3,5,7)$ & $(7,9,10)$ \\
$\boldsymbol{F}_{1} \cdot \boldsymbol{C}_{4}$ & $\mathrm{HI}$ & $\mathrm{HI}$ & $\mathrm{MI}$ & $\boldsymbol{F}_{1} \cdot \boldsymbol{C}_{4}$ & $(7,9,10)$ & $(7,9,10)$ & $(3,5,7)$ \\
$\boldsymbol{F}_{2} \cdot \boldsymbol{C}_{1}$ & $\mathrm{~L}$ & $\mathrm{ML}$ & $\mathrm{ML}$ & $\boldsymbol{F}_{2} \cdot \boldsymbol{C}_{1}$ & $(0,1,3)$ & $(1,3,5)$ & $(1,3,5)$ \\
$\boldsymbol{F}_{2} \cdot \boldsymbol{C}_{2}$ & $\mathrm{MH}$ & $\mathrm{ML}$ & $\mathrm{ML}$ & $\boldsymbol{F}_{2} \cdot \boldsymbol{C}_{2}$ & $(5,7,9)$ & $(1,3,5)$ & $(1,3,5)$ \\
$\boldsymbol{F}_{2} \cdot \boldsymbol{C}_{3}$ & $\mathrm{MH}$ & $\mathrm{MH}$ & $\mathrm{MI}$ & $\boldsymbol{F}_{2} \cdot \boldsymbol{C}_{3}$ & $(5,7,9)$ & $(5,7,9)$ & $(3,5,7)$ \\
$\boldsymbol{F}_{2} \cdot \boldsymbol{C}_{4}$ & $\mathrm{VI}$ & $\mathrm{HI}$ & $\mathrm{VI}$ & $\boldsymbol{F}_{2} \cdot \boldsymbol{C}_{4}$ & $(9,10,10)$ & $(7,9,10)$ & $(9,10,10)$ \\
$\boldsymbol{F}_{3} \cdot \boldsymbol{C}_{1}$ & $\mathrm{MH}$ & $\mathrm{HI}$ & $\mathrm{VI}$ & $\boldsymbol{F}_{3} \cdot \boldsymbol{C}_{1}$ & $(5,7,9)$ & $(7,9,10)$ & $(9,10,10)$ \\
$\boldsymbol{F}_{3} \cdot \boldsymbol{C}_{2}$ & $\mathrm{MI}$ & $\mathrm{HI}$ & $\mathrm{HI}$ & $\boldsymbol{F}_{3} \cdot \boldsymbol{C}_{2}$ & $(3,5,7)$ & $(7,9,10)$ & $(7,9,10)$ \\
$\boldsymbol{F}_{3} \cdot \boldsymbol{C}_{3}$ & $\mathrm{MH}$ & $\mathrm{VI}$ & $\mathrm{VI}$ & $\boldsymbol{F}_{3} \cdot \boldsymbol{C}_{3}$ & $(5,7,9)$ & $(9,10,10)$ & $(9,10,10)$ \\
$\boldsymbol{F}_{3} \cdot \boldsymbol{C}_{4}$ & $\mathrm{HI}$ & $\mathrm{HI}$ & $\mathrm{VI}$ & $\boldsymbol{F}_{3} \cdot \boldsymbol{C}_{4}$ & $(7,9,10)$ & $(7,9,10)$ & $(9,10,10)$ \\
$\boldsymbol{F}_{4} \cdot \boldsymbol{C}_{1}$ & $\mathrm{HI}$ & $\mathrm{VI}$ & $\mathrm{HI}$ & $\boldsymbol{F}_{4} \cdot \boldsymbol{C}_{1}$ & $(7,9,10)$ & $(9,10,10)$ & $(7,9,10)$ \\
$\boldsymbol{F}_{4} \cdot \boldsymbol{C}_{2}$ & $\mathrm{MH}$ & $\mathrm{HI}$ & $\mathrm{MH}$ & $\boldsymbol{F}_{4} \cdot \boldsymbol{C}_{2}$ & $(5,7,9)$ & $(7,9,10)$ & $(5,7,9)$ \\
$\boldsymbol{F}_{4} \cdot \boldsymbol{C}_{3}$ & $\mathrm{HI}$ & $\mathrm{HI}$ & $\mathrm{HI}$ & $\boldsymbol{F}_{4} \cdot \boldsymbol{C}_{3}$ & $(7,9,10)$ & $(7,9,10)$ & $(7,9,10)$ \\
$\boldsymbol{F}_{4} \cdot \boldsymbol{C}_{4}$ & $\mathrm{HI}$ & $\mathrm{HI}$ & $\mathrm{HI}$ & $\boldsymbol{F}_{4} \cdot \boldsymbol{C}_{4}$ & $(7,9,10)$ & $(7,9,10)$ & $(7,9,10)$ \\
$\boldsymbol{F}_{5} \cdot \boldsymbol{C}_{1}$ & $\mathrm{MH}$ & $\mathrm{MH}$ & $\mathrm{HI}$ & $\boldsymbol{F}_{5} \cdot \boldsymbol{C}_{1}$ & $(5,7,9)$ & $(5,7,9)$ & $(7,9,10)$ \\
$\boldsymbol{F}_{5} \cdot \boldsymbol{C}_{2}$ & $\mathrm{HI}$ & $\mathrm{HI}$ & $\mathrm{HI}$ & $\boldsymbol{F}_{5} \cdot \boldsymbol{C}_{2}$ & $(7,9,10)$ & $(7,9,10)$ & $(7,9,10)$ \\
$\boldsymbol{F}_{5} \cdot \boldsymbol{C}_{3}$ & $\mathrm{MH}$ & $\mathrm{HI}$ & $\mathrm{HI}$ & $\boldsymbol{F}_{5} \cdot \boldsymbol{C}_{3}$ & $(5,7,9)$ & $(7,9,10)$ & $(7,9,10)$ \\
$\boldsymbol{F}_{5} \cdot \boldsymbol{C}_{4}$ & $\mathrm{MH}$ & $\mathrm{HI}$ & $\mathrm{HI}$ & $\boldsymbol{F}_{5} \cdot \boldsymbol{C}_{4}$ & $(5,7,9)$ & $(7,9,10)$ & $(7,9,10)$ \\
\hline
\end{tabular}


In the next step, the fuzzy decision matrix (Table 15), normalized fuzzy decision matrix (Table 16), and weighted normalized matrix (Table 17) were computed.

Table 15. The fuzzy decision matrix and fuzzy weights of five factors.

\begin{tabular}{cllll}
\hline Factor & \multicolumn{1}{c}{$\boldsymbol{C}_{\mathbf{1}}$} & \multicolumn{1}{c}{$\boldsymbol{C}_{\mathbf{2}}$} & \multicolumn{1}{c}{$\boldsymbol{C}_{\mathbf{3}}$} & \multicolumn{1}{c}{$\boldsymbol{C}_{\mathbf{4}}$} \\
\hline $\boldsymbol{F}_{1}$ & $(4.33,6.33,8.33)$ & $(3,5,7)$ & $(5.67,7.67,9)$ & $(5.67,7.67,9)$ \\
$\boldsymbol{F}_{2}$ & $(0.67,2.33,4.33)$ & $(2.33,4.33,6.33)$ & $(4.33,6.33,8.33)$ & $(8.33,9.67,10)$ \\
$\boldsymbol{F}_{3}$ & $(7,8.67,9.67)$ & $(5.67,7.67,9)$ & $(7.67,9,9.67)$ & $(7.67,9.33,10)$ \\
$\boldsymbol{F}_{4}$ & $(7.67,9.33,10)$ & $(5.67,7.67,9.33)$ & $(7,9,10)$ & $(7,9,10)$ \\
$\boldsymbol{F}_{5}$ & $(5.67,7.67,9.33)$ & $(7,9,10)$ & $(6.33,8.33,9.67)$ & $(6.33,8.33,9.67)$ \\
weight & $(0.2,0.29,0.43)$ & $(0.18,0.29,0.47)$ & $(0.13,0.21,0.34)$ & $(0.14,0.21,0.3)$ \\
\hline
\end{tabular}

Table 16. The normalized fuzzy decision matrix.

\begin{tabular}{cllll}
\hline Factor & \multicolumn{1}{c}{$\boldsymbol{C}_{\mathbf{1}}$} & \multicolumn{1}{c}{$\boldsymbol{C}_{\mathbf{2}}$} & \multicolumn{1}{c}{$\boldsymbol{C}_{\mathbf{3}}$} & \multicolumn{1}{c}{$\boldsymbol{C}_{\boldsymbol{4}}$} \\
\hline $\boldsymbol{F}_{1}$ & $(0.43,0.63,0.83)$ & $(0.3,0.5,0.7)$ & $(0.5,70.77,0.9)$ & $(0.57,0.77,0.9)$ \\
$\boldsymbol{F}_{2}$ & $(0.07,0.23,0.43)$ & $(0.23,0.43,0.63)$ & $(0.43,0.63,0.83)$ & $(0.83,0.97,1)$ \\
$\boldsymbol{F}_{3}$ & $(0.7,0.87,0.97)$ & $(0.57,0.77,0.9)$ & $(0.77,0.9,0.97)$ & $(0.77,0.93,1)$ \\
$\boldsymbol{F}_{4}$ & $(0.77,0.93,1)$ & $(0.57,0.77,0.93)$ & $(0.7,0.9,1)$ & $(0.7,0.9,1)$ \\
$\boldsymbol{F}_{5}$ & $(0.57,0.77,0.93)$ & $(0.7,0.9,1)$ & $(0.63,0.83,0.97)$ & $(0.63,0.83,0.97)$ \\
\hline
\end{tabular}

Table 17. The fuzzy weighted normalized decision matrix.

\begin{tabular}{cclll}
\hline Factor & \multicolumn{1}{c}{$\boldsymbol{C}_{\mathbf{1}}$} & \multicolumn{1}{c}{$\boldsymbol{C}_{\mathbf{2}}$} & \multicolumn{1}{c}{$\boldsymbol{C}_{\mathbf{3}}$} & \multicolumn{1}{c}{$\boldsymbol{C}_{\mathbf{4}}$} \\
\hline $\boldsymbol{F}_{1}$ & $(0.08,0.19,0.36)$ & $(0.05,0.15,0.33)$ & $(0.07,0.16,0.3)$ & $(0.08,0.16,0.27)$ \\
$\boldsymbol{F}_{2}$ & $(0.01,0.07,0.19)$ & $(0.04,0.13,0.3)$ & $(0.06,0.13,0.28)$ & $(0.12,0.2,0.3)$ \\
$\boldsymbol{F}_{3}$ & $(0.14,0.25,0.42)$ & $(0.1,0.23,0.42)$ & $(0.1,0.19,0.33)$ & $(0.11,0.19,0.3)$ \\
$\boldsymbol{F}_{4}$ & $(0.15,0.27,0.43)$ & $(0.1,0.23,0.44)$ & $(0.09,0.19,0.34)$ & $(0.1,0.19,0.3)$ \\
$\boldsymbol{F}_{5}$ & $(0.11,0.23,0.41)$ & $(0.13,0.26,0.47)$ & $(0.08,0.17,0.33)$ & $(0.09,0.17,0.29)$ \\
\hline
\end{tabular}

After that, the distance of each alternative from the fuzzy positive ideal matrix $\left(\mathrm{d}^{*}\right)$ and fuzzy negative ideal matrix (d-) using Equations (15)-(18) and the closeness coefficient $\left(C_{i}\right)$ of each alternative was computed. The $C C_{i}$ is calculated using Equation (19) (Table 18). In the next step, the factors are ranked according to $C C_{i}$. The best alternative is closest to the FPIS and farthest from the FNIS.

Table 18. Closeness coefficient $\left(C C_{i}\right)$ of the five factors.

\begin{tabular}{cccccc}
\hline & $\boldsymbol{F}_{\mathbf{1}}$ & \multicolumn{1}{c}{$\boldsymbol{F}_{\mathbf{2}}$} & $\boldsymbol{F}_{\mathbf{3}}$ & $\boldsymbol{F}_{\mathbf{4}}$ & $\boldsymbol{F}_{\mathbf{5}}$ \\
\hline$d_{i}^{*}$ & 3.28887129 & 3.40961956 & 3.10431321 & 3.09089235 & 3.1217108 \\
$d_{i}^{-}$ & 0.84075017 & 0.7069268 & 1.01839507 & 1.04164368 & 1.01647544 \\
$C_{i}$ & 0.20359013 & 0.17172813 & 0.24702089 & 0.25205919 & 0.24563308 \\
Ranking & 4 & 5 & 2 & 1 & 3 \\
\hline
\end{tabular}

A comparison of $d_{1}^{*}, d_{2}^{*}, \ldots, d_{5}^{*}$ and $d_{1}^{-}, d_{2}^{-}, \ldots, d_{5}^{-} \mathrm{d}$ d-values which reflect the maintenance factors is shown in Figure 8. 


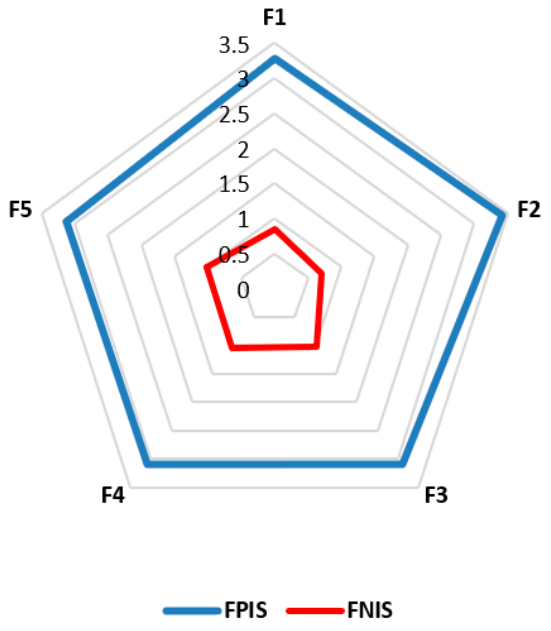

(a)

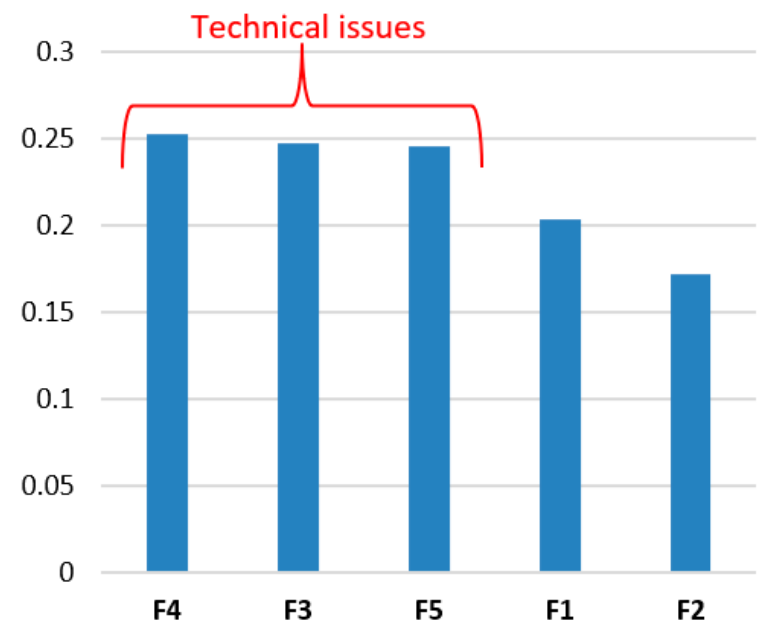

(b)

Figure 8. Fuzzy technique for order preference by similarity to ideal solution (F-TOPSIS) results: (a) fuzzy positive ideal solution (FPIS) and fuzzy negative ideal solution (FNIS) distance; (b) closeness ratio versus factor.

It is observed that factor $\mathrm{F} 4$ "The usage of $\mathrm{M} \& \mathrm{O}$ data collection and processing systems" has the highest closeness ratio; therefore, it is the highest ranked factor. Based on the MICMAC approach, it has emerged as a major independent driver factor for supporting sustainable manufacturing challenges. The next important identified factors are F3 "Implementation of preventive and prognostic service strategies" and F5 "Modernization of machines and devices". These factors according to the MICMAC approach were categorized also as "Linkage factors". It should be noted that these most important factors are related to technical issues. That is why the company should pay attention to these factors and firstly implement the activities in these areas to support achieving sustainable manufacturing challenges.

\subsection{Sensitivity Analysis}

To examine the influence of the preferences given by the decision-makers for the calculated closeness ratio, sensitivity analysis was performed. During the analysis, 10 cases were conducted and performed in R software (version 3.6.1). In each case, the lowest rating increased by one for each criterion $\left(\mathrm{F}_{\mathrm{i}}+\right)$, for example, from $\mathrm{MI}$ to $\mathrm{MH}$, or the highest rating decreased by one level for each criterion $\left(\mathrm{F}_{\mathrm{i}}-\right)$. The details of the obtained rankings of the origin (without changes) results of the 10 cases are shown in Table 19, and the closeness coefficient is shown in Figure 9.

Table 19. Sensitivity analysis results—-the factor ranking.

\begin{tabular}{cccccccccccc}
\hline Rank. & Original Rank & $\mathbf{F}_{\mathbf{1}}-$ & $\mathbf{F}_{\mathbf{1}}+$ & $\mathbf{F}_{\mathbf{2}}-$ & $\mathbf{F}_{\mathbf{2}}+$ & $\mathbf{F}_{\mathbf{3}}-$ & $\mathbf{F}_{\mathbf{3}}+$ & $\mathbf{F}_{\mathbf{4}}-$ & $\mathbf{F}_{\mathbf{4}}+$ & $\mathbf{F}_{5}-$ & $\mathbf{F}_{5}+$ \\
\hline $\mathbf{1}$ & $\mathrm{A}_{4}$ & $\mathrm{~A}_{4}$ & $\mathrm{~A}_{4}$ & $\mathrm{~A}_{4}$ & $\mathrm{~A}_{4}$ & $\mathrm{~A}_{4}$ & $\mathrm{~A}_{3}$ & $\mathrm{~A}_{3}$ & $\mathrm{~A}_{4}$ & $\mathrm{~A}_{4}$ & $\mathrm{~A}_{5}$ \\
$\mathbf{2}$ & $\mathrm{A}_{3}$ & $\mathrm{~A}_{3}$ & $\mathrm{~A}_{3}$ & $\mathrm{~A}_{3}$ & $\mathrm{~A}_{3}$ & $\mathrm{~A}_{5}$ & $\mathrm{~A}_{4}$ & $\mathrm{~A}_{5}$ & $\mathrm{~A}_{3}$ & $\mathrm{~A}_{3}$ & $\mathrm{~A}_{4}$ \\
$\mathbf{3}$ & $\mathrm{A}_{5}$ & $\mathrm{~A}_{5}$ & $\mathrm{~A}_{5}$ & $\mathrm{~A}_{5}$ & $\mathrm{~A}_{5}$ & $\mathrm{~A}_{3}$ & $\mathrm{~A}_{5}$ & $\mathrm{~A}_{4}$ & $\mathrm{~A}_{5}$ & $\mathrm{~A}_{5}$ & $\mathrm{~A}_{3}$ \\
$\mathbf{4}$ & $\mathrm{A}_{1}$ & $\mathrm{~A}_{1}$ & $\mathrm{~A}_{1}$ & $\mathrm{~A}_{1}$ & $\mathrm{~A}_{1}$ & $\mathrm{~A}_{1}$ & $\mathrm{~A}_{1}$ & $\mathrm{~A}_{1}$ & $\mathrm{~A}_{1}$ & $\mathrm{~A}_{1}$ & $\mathrm{~A}_{1}$ \\
$\mathbf{5}$ & $\mathrm{A}_{2}$ & $\mathrm{~A}_{2}$ & $\mathrm{~A}_{2}$ & $\mathrm{~A}_{2}$ & $\mathrm{~A}_{2}$ & $\mathrm{~A}_{2}$ & $\mathrm{~A}_{2}$ & $\mathrm{~A}_{2}$ & $\mathrm{~A}_{2}$ & $\mathrm{~A}_{2}$ & $\mathrm{~A}_{2}$ \\
\hline
\end{tabular}




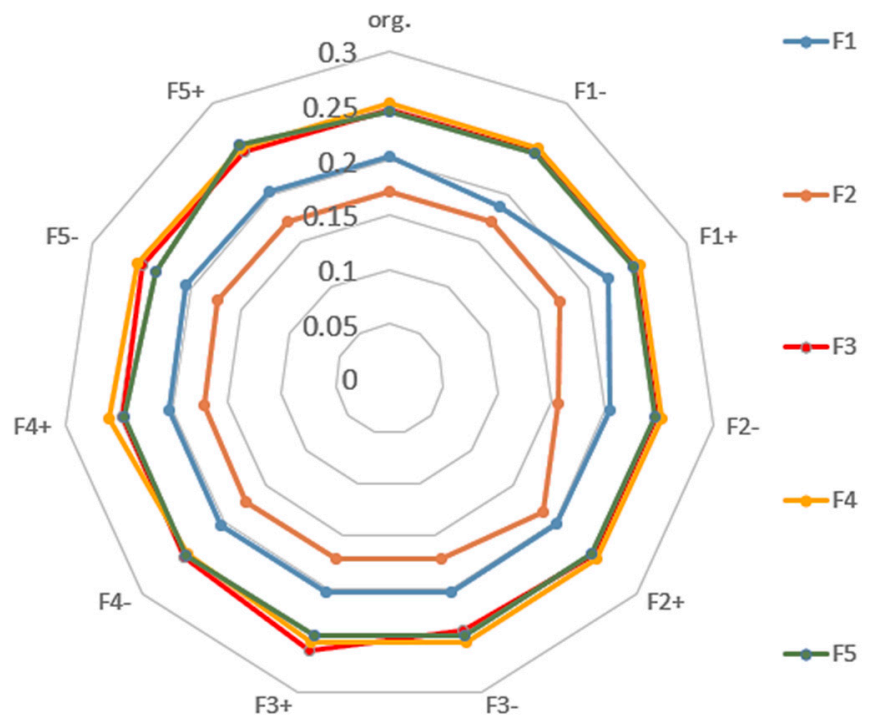

Figure 9. Sensitivity analysis results—closeness ratio versus factor.

The three dominant factors $\left(\mathrm{F}_{3}, \mathrm{~F}_{4}, \mathrm{~F}_{5}\right)$ changed their position in the ranking, indicating that with such small differences in the closeness ratio they should be treated as equally important. The other two clearly smaller factors $\left(F_{1}\right.$ and $\left.F_{2}\right)$, for which the difference in coefficients was clearly visible, did not change their positions in the ranking, indicating that a slight underestimation or overestimation of the ratings by any of the decision-makers did not have a significant impact on the received ranking.

\section{Conclusions}

In this study, an integrated approach (MICAMC, F-AHP, and F-TOPSIS) was used to analyze the maintenance factors influencing the implementation of sustainable manufacturing challenges from a tactical perspective, and to rank them taking into account the specificity of an operational context of an enterprise. Ten maintenance factors for achieving sustainable manufacturing challenges have been described based on a literature analysis and discussion with experts from the industry. After that, MICMAC analysis was used to identify the key maintenance factors. Based on the influence and dependence value, the factors involved in the study were classified into four clusters: I-autonomous factors, II-dependent factors, III-linkage factors, and IV-independent factors. Factors from the clusters III and IV were considered key maintenance factors affecting sustainable manufacturing and were taken as an inputs for F-TOPSIS analysis. These factors were "Cooperation with P\&Q departments", "Implementation of preventive and prognostic service strategies", "Modernization of machines and devices", "The usage of M\&O data collection and processing systems", and "Cooperation with the SHE department". Then, the assessment criteria of maintenance factors were identified, and their relative weights were determined by fuzzy AHP. Finally, the results of MICMAN and fuzzy AHP analyses were used as an input to rank the maintenance factors by the fuzzy TOPSIS method. As a result of this method, the most important maintenance factors that have an impact on sustainable manufacturing processes were identified.

The analysis showed that technical factors ("The usage of M\&O data collection and processing systems", "Implementation of preventive and prognostic service strategies", and "Modernization of machines and devices") are rated as the most important and influential for sustainable manufacturing. It is characteristic that these three indicated factors (the first two directly, the third indirectly) are related to the activities whose horizon is defined as Industry 4.0. The wide collection of data and their analysis, in particular, the possibility of self-diagnosis of machines and forecasting their condition, is one of the pillars of this idea. These activities are related to investments in technical infrastructure, especially the 
modernization of machines and development of data acquisition and analysis systems, with particular emphasis on the so-called Internet of Things and cloud computing. The results of this study are compatible with the research conducted by $[9,10]$. Consequently, the methodology presented in this paper could assist company managers in the adequate choice of maintenance factors that will influence the social, environmental, and economic aspects of manufacturing.

The proposed solution has also some limitations. Firstly, the analysis of the assessment of the importance of factors influencing sustainability concerns selected a company from a specific industry, hence the results obtained cannot be generalized. Secondly, the assessment criteria of the maintenance factors were determined by experts from that company and are related to the internal and external context of the organization. This represents a limitation of the proposed approach, as it is difficult to benchmark sustainability performance across companies in different sectors, as well as sometimes in the same sector.

By reviewing the results of these studies in terms of theory and practice, directions for further research can be formulated. Due to the intensive development of Industry 4.0 technologies and their impact on meeting the challenges of sustainable production $[3,132,133]$, in subsequent stages of research it would be necessary to consider the potential benefits of these technologies in supporting maintenance processes towards sustainable production. In particular, research should focus on intelligent systems for collecting, processing and analyzing data, and the benefits of new business models in maintenance management. This is the first proposed research direction. The second direction of future research concerns MCDM methods. In the literature on the subject, there are also other MCDM methods for problem analysis that can be used in future research in this area, such as ELECTRE (Elimination et choix traduisant la realité), VICOR (Visekriterijumska optimizacija i kompromisno resenje) or extensions of the TOPSIS method based on the application of intuitionistic, grey, and neutrosophic numbers.

Author Contributions: Conceptualization, M.J.-K.; K.A. and C.Q.; methodology, M.J.-K. and K.A.; formal analysis, M.J.-K.; R.W. and K.A.; investigation, M.J.-K.; R.W. and K.A.; writing—original draft preparation, M.J.-K., K.A. and R.W.; writing—review and editing, R.W.; D.M.; B.S.; C.Q.; Y.R.; visualization, M.J.-K.; K.A.; B.S.; C.Q. and Y.R.; supervision, D.M.; project administration, M.J.-K.; D.M. and K.A.; funding acquisition, M.J.-K. All authors have read and agreed to the published version of the manuscript.

Funding: This article was funded by Poznan University of Technology, Faculty of Engineering Management [project number: 0811/SBAD/1013].

Institutional Review Board Statement: Not applicable.

Informed Consent Statement: Not applicable.

Data Availability Statement: No new data were created and analyzed in this study. Data sharing is not applicable to this article.

Conflicts of Interest: The authors declare no conflict of interest.

\section{References}

1. Division for Sustainable Development Goals. Sustainable Development Knowledge Platform. United Nations. Available online: https:/ / sustainabledevelopment.un.org/ (accessed on 20 November 2020).

2. Moldavska, A.; Welo, T. The concept of sustainable manufacturing and its definitions: A content-analysis based literature review. J. Clean. Prod. 2017, 166, 744-755. [CrossRef]

3. Sartal, A.; Bellas, R.; Mejías, A.M.; García-Collado, A. The sustainable manufacturing concept, evolution and opportunities within Industry 4.0: A literature review. Adv. Mech. Eng. 2020. [CrossRef]

4. Kannegiesser, M.; Günther, H.O. Sustainable development of global supply chains-Part 1: Sustainability optimization framework. Flex. Serv. Manuf. J. 2014, 26, 24-47. [CrossRef]

5. Molamohamadi, Z.; Ismail, N. Developing a new scheme for sustainable manufacturing. Int. J. Mat. Mech. Manuf. 2013, 1, 1-5. [CrossRef]

6. Veleva, V.; Ellenbecker, M. Indicators of sustainable production: Framework and methodology. J. Clean. Prod. 2001, 9, 519-549. [CrossRef] 
7. Iung, B.; Levrat, E. Advanced maintenance services for promoting sustainability. Procedia CIRP 2014, 22, 15-22. [CrossRef]

8. Sénéchal, O. Performance indicators nomenclatures for decision making in sustainable conditions based maintenance. IFAC PapersOnLine 2018, 51, 1137-1142. [CrossRef]

9. Franciosi, C.; Di Pasquale, V.; Iannone, R.; Miranda, S. Multi-stakeholder perspectives on indicators for sustainable maintenance performance in production contexts: An exploratory study. J. Qual. Maint. Eng. 2020. [CrossRef]

10. Holgado, M.; Macchi, M.; Evans, S. Exploring the impacts and contributions of maintenance function for sustainable manufacturing. Int. J. Prod. Res. 2020, 58, 7292-7310. [CrossRef]

11. Amrina, E.; Yulianto, A.; Kamil, I. Fuzzy multi criteria approach for sustainable maintenance evaluation in rubber industry. Procedia Manuf. 2019, 33, 538-545. [CrossRef]

12. Franciosi, C.; Voisin, A.; Miranda, S.; Riemma, S.; Iung, B. Measuring maintenance impacts on sustainability of manufacturing industries: From a systematic literature review to a framework proposal. J. Clean. Prod. 2020, 260, 121065. [CrossRef]

13. Jasiulewicz-Kaczmarek, M.; Żywica, P.; Gola, A. Fuzzy set theory driven maintenance sustainability performance assessment model: A multiple criteria approach. J. Intel. Manuf. 2021. [CrossRef]

14. Jasiulewicz-Kaczmarek, M. Identification of maintenance factors influencing the development of sustainable production processes-A pilot study. In IOP Conference Series: Materials Science and Engineering; IOP Publishing: Bristol, UK, 2018 ; p. 062014.

15. Singh, R.K.; Gupta, A. Framework for sustainable maintenance system: ISM-fuzzy MICMAC and TOPSIS approach. Ann. Oper. Res. 2020, 290, 643-676. [CrossRef]

16. Balali, A.; Valipour, A.; Edwards, R.; Moehler, R. Ranking effective risks on human resources threats in natural gas supply projects using ANP-COPRAS method: Case study of Shiraz. Reliab. Eng. Syst. Saf. 2021, 208, 107442. [CrossRef]

17. Ighravwe, D.E.; Oke, S.A. Applying Fuzzy Multi-Criteria Decision-Making Framework in Evaluating Maintenance Systems with an Emphasis on Human Tasks and Errors. Mahasarakham Int. J. Eng. Technol. 2021, 7, 67-77.

18. EN 13306:2017. Maintenance-Maintenance Terminology; CEN-CENELEC Management Centre: Bruxelles, Belgium, 2017.

19. Jasiulewicz-kaczmarek, M.; Antosz, K.; Żywica, P.; Mazurkiewicz, D.; Sun, B.; Ren, Y. Framework of machine criticality assessment with criteria interactions. Eksploat. Niezawodn. 2021, 23, 207-220. [CrossRef]

20. Yan, J. Machinery Prognostics and Prognosis Oriented Maintenance Management; John Wiley \& Sons: Singapore, $2015 ;$ p. 4.

21. Takata, S. Maintenance-centered circular Manufacturing. Procedia CIRP 2013, 11, 23-31. [CrossRef]

22. Takata, S.; Kimura, F.; Houten, F.J.A.M.; Westkämper, E.; Shpitalni, M.; Ceglarek, D.; Jay Lee, J. Maintenance: Changing role in life cycle management. Ann. CIRP 2004, 53, 643-656. [CrossRef]

23. Ayu, K.; Yunusa-Kaltungo, A. A Holistic Framework for Supporting Maintenance and Asset Management Life Cycle Decisions for Power Systems. Energies 2020, 13, 1937. [CrossRef]

24. Kowalski, A.; Blichtarski, M. The Method of Determining the Optimal Life Cycle of the Mining Machine. IOP Conf. Ser. Mater. Sci. Eng. 2019, 679, 012015. [CrossRef]

25. Hami, N.; Ibrahim, Y.M.; Yamin, F.M.; Shafie, S.M.; Abdulameer, S.S. The Moderating Role of Sustainable Maintenance on the Relationship between Sustainable Manufacturing Practices and Social Sustainability: A Conceptual Framework. Int. J. Eng. Adv. Tech. 2019, 8, 222-228. [CrossRef]

26. Liyanage, J.P.; Badurdeen, F.; Ratnayake, R.C.M. Industrial Asset Maintenance and Sustainability Performance: Economical, Environmental, and Societal Implications. In Handbook of Maintenance Management and Engineering; Springer: London, UK, 2009; pp. 665-693. [CrossRef]

27. Hu, Q.; Bai, Y.; Zhao, J.; Cao, W. Modeling spare parts demands forecast under two-dimensional preventive maintenance policy. Math. Probl. Eng. 2015, 4, 1-9. [CrossRef]

28. Lewis, A.; Elmualim, A. Linking energy and maintenance management for sustainability through three American case studies. Facilities 2011, 29, 243-254. [CrossRef]

29. Yabrudy-Mercado, D.E.; López-Sarria, B.S.; Fajardo-Cuadro, J.G.; Cardona-Agudelo, C.A. Indicators for maintenance planning based on energy efficiency in heat exchanger networks. Sci. Tech. Año XXV 2020, 25, 367-371. [CrossRef]

30. Xia, T.; Xi, L.; Du, S.; Xiao, L.; Pan, E. Energy-Oriented Maintenance Decision-Making for Sustainable Manufacturing Based on Energy Saving Window. J. Manuf. Sci. Eng. 2018, 140, 051001. [CrossRef]

31. Ndhaief, N.; Nidhal, R.; Hajji, A.; Bistorin, O. Environmental Issue in an Integrated Production and Maintenance Control of Unreliable Manufacturing/Remanufacturing Systems. Int. J. Prod. Res. 2020, 58, 4182-4200. [CrossRef]

32. Duran, O.; Afonso, P.S.L.P. An activity based costing decision model for life cycle economic assessment in spare parts logistic management. Int. J. Prod. Econ. 2020, 222, 107499. [CrossRef]

33. Turner, C.; Okorie, O.; Emmanouilidis, C.; Oyekan, J. A Digital Maintenance Practice Framework for Circular Production of Automotive. IFAC PapersOnLine 2020, 53, 19-24. [CrossRef]

34. Noroozi, A.; Khakzad, N.; Khan, F.; MacKinnon, S.; Abbassi, R. The role of human error in risk analysis: Application to pre-and post-maintenance procedures of process facilities. Reliab. Eng. Syst. Saf. 2013, 119, 251-258. [CrossRef]

35. Fraser, K.; Hvolby, H.H.; Tseng, T.L. Maintenance management models: A study of the published literature to identify empirical evidence. Int. J. Qual. Reliab. Manag. 2015, 32, 635-664. [CrossRef]

36. Duperrin, J.C.; Godet, M. Methode de Hierarchization des Elements d'un Systeme (Method for Hierarchizing the Elements of a System); Report CEA-R-4541; Paris, France, 1973; pp. 41-45. Available online: https://hal-lara.archives-ouvertes.fr/hal-02185432 / document (accessed on 1 March 2021). 
37. Loska, A. Exploitation assessment of selected technical objects using taxonomic methods. Eksploat. Niezawod. 2013, 15, 1-8.

38. Jiang, X.; Lu, K.; Xia, B.; Liu, Y.; Cui, C. Using Integrated FISM-MICMAC Approach. Sustainability 2019, 11, 5206. [CrossRef]

39. Saaty, T.L. Decision Making for Leaders: The Analytical Hierarchy Process for Decisions in a Complex World; Lifetime Learning Publications: Belmont, CA, USA, 1982.

40. Kusumawardani, R.P.; Agintiara, M. Application of fuzzy AHP-TOPSIS method for decision making in human resource manager selection process. Procedia Comput. Sci. 2015, 72, 638-646. [CrossRef]

41. Yucenur, G.N. A producer selection problem: A case study from Turkish food industry. Beykent Univ. J. Sci. Eng. 2017, 10, 185-212. [CrossRef]

42. Shaygan, A.; Testik, Ö.M. A fuzzy AHP-based methodology for project prioritization and selection. Soft Comput. 2017, 23, 1309-1319. [CrossRef]

43. Hwang, C.L.; Yoon, K. Multiple Attribute Decision Making: Methods and Applications: A State-of-the-Art Survey; Springer: Berlin, Germany, 1981; p. 13.

44. Palczewski, K.; Sałabun, W. The fuzzy TOPSIS applications in the last decade. Procedia Comput. Sci. 2019, 159, $2294-2303$. [CrossRef]

45. Gumus, A.T. Evaluation of hazardous waste transportation firms by using a two step fuzzy AHP and TOPSIS methodology. Expert Syst. Appl. 2009, 36, 4067-4074. [CrossRef]

46. Chang, D.Y. Applications of the extent analysis method on fuzzy AHP. Eur. J. Oper. Res. 1996, 95, 649-655. [CrossRef]

47. Chang, D.Y. Extent analysis and synthetic decision. Optim. Tech. Appl. 1992, 1, 352-355.

48. Zadeh, L.A. Fuzzy logic and approximate reasoning. Synthese 1975, 30, 407-428. [CrossRef]

49. Giachetti, R.E.; Young, R.E. A parametric representation of fuzzy numbers and their arithmetic operators. Fuzzy Sets Syst. 1997, 91, 185-202. [CrossRef]

50. Torfi, F.; Farahani, R.Z.; Rezapour, S. Fuzzy AHP to determine the relative weights of evaluation criteria and Fuzzy TOPSIS to rank the alternatives. Appl. Soft Comput. 2010, 10, 520-528. [CrossRef]

51. Liu, Y.; Eckert, C.M.; Earl, C. A review of fuzzy AHP methods for decision-making with subjective judgements. Expert Syst. Appl. 2020, 161, 113738. [CrossRef]

52. Godet, M. From Anticipation to Action: A Handbook of Strategic Prospective; UNESCO Publishing: Paris, France, 1994.

53. Chen, C.T. Extensions of the TOPSIS for group decision-making under fuzzy environment. Fuzzy Sets Syst. 2000, 114, 1-9. [CrossRef]

54. Piltan, F.; Kim, J.M. Fault Diagnosis of Bearings Using an Intelligence-Based Autoregressive Learning Lyapunov Algorithm. Int. J. Comput. Intell. Syst. 2021, in press. [CrossRef]

55. Teixeira, C.; Lopes, I.; Figueiredo, M. Classification methodology for spare parts management combining maintenance and logistics perspectives. J. Manag. Anal. 2018, 5, 116-135. [CrossRef]

56. Antosz, K.; Ratnayake, R.M.C. Spare parts' criticality assessment and prioritization for enhancing manufacturing systems' availability and reliability. J. Manuf. Syst. 2019, 50, 212-225. [CrossRef]

57. Wakiru, J.; Pintelon, L.; Muchiri, P.N.; Chemweno, P.K. A review on lubricant condition monitoring information analysis for maintenance decision support. Mech. Syst. Signal. Pract. 2019, 118, 108-132. [CrossRef]

58. Choi, B.; Suh, J.H. Forecasting Spare Parts Demand of Military Aircraft: Comparisons of Data Mining Techniques and Managerial Features from the Case of South Korea. Sustainability 2020, 12, 6045. [CrossRef]

59. Zhu, S.; Jaarsveld, W.V.; Dekker, R. Spare parts inventory control based on maintenance planning. Reliab. Eng. Syst. Saf. 2020, 193, 106600. [CrossRef]

60. Lejon, E.; Jeppsson, P. Integrating use phase information and virtual product representation to support Functional Products. Procedia CIRP 2015, 38, 204-209. [CrossRef]

61. Sun, Y.; Qi, Z. How modularity influences product innovation. Manag. Decis. 2020, 58, 2743-2761. [CrossRef]

62. Wu, Q.; Liao, K.; Deng, X.; Marsillac, E. Achieving automotive suppliers- mass customization through modularity. J. Manuf. Technol. Manag. 2019, 31, 306-329. [CrossRef]

63. Zhang, M.; Guo, H.; Huo, B.; Zhao, X.; Huang, J. Linking supply chain quality integration with mass customization and product modularity. Int. J. Prod. Econ. 2019, 207, 227-235. [CrossRef]

64. Blaise, J.C.; Levrat, E.; Iung, B. Process approach-based methodology for safe maintenance operation: From concepts to SPRIMI software prototype. Saf. Sci. 2014, 70, 99-113. [CrossRef]

65. Estarrona, U.M.; Seneviratne, D.; Villarejo, R.; Galar, D. The New Asset Management: Implications of Servitization in Circular Economy. J. Ind. Eng. Manag. Sci. 2019, 6, 109-120. [CrossRef]

66. Ren, W.; Wu, K.; Gu, Q.; Hu, Y. Intelligent decision making for service providers selection in maintenance service network: An adaptive fuzzy-neuro approach. Knowl. Based Syst. 2020, 190, 105263. [CrossRef]

67. Lee, J.; Ardakani, H.D.; Yang, S.; Bagheri, B. Industrial big data analytics and cyber-physical systems for future maintenance \& service innovation. Procedia CIRP 2015, 38, 3-7.

68. Fathi, M.; Holland, A.; Abramovici, M.; Neubach, M. Advanced Condition Monitoring Services in Product Lifecycle Management. In Proceedings of the 2007 IEEE International Conference on Information Reuse and Integration, Las Vegas, NV, USA, 13-15 August 2007; pp. 245-250. 
69. Macchi, M.; Fumagalli, L.; Pinto, R.; Cavalieri, S. A decision making framework for managing maintenance spare parts in case of lumpy demand: An action research in the avionic sector. In Service Parts Management Demand Forecasting and Inventory Control; Altay, N., Litteral, L.A., Eds.; Springer: London, UK, 2011; pp. 171-202.

70. Roy, R.; Stark, R.; Tracht, K.; Takata, S.; Mori, M. Continuous maintenance and the future-Foundations and technological challenges. CIRP Ann. Manuf. Technol. 2016, 65, 667-688. [CrossRef]

71. Kozłowski, E.; Kowalska, B.; Kowalski, D.; Mazurkiewicz, D. Survival Function in the Analysis of the Factors Influencing the Reliability of Water Wells Operation. Water Resour. Manag. 2019, 33, 4909-4921. [CrossRef]

72. Paprocka, I. The Model of Maintenance Planning and Production Scheduling for Maximising Robustness. Int. J. Prod. Res. 2019, 57, 4480-4501. [CrossRef]

73. Erfanian, M.; Pirayesh, M. Integration Aggregate Production Planning and Maintenance Using Mixed Integer Linear Programming. In Proceedings of the 2016 IEEE International Conference on Industrial Engineering and Engineering Management (IEEM), Bali, Indonesia, 4-7 December 2016; pp. 927-930. [CrossRef]

74. Shankar, M.; Kumar, P.; Kannan, D.U. Analyzing the Drivers of Advanced Sustainable Manufacturing System Using AHP Approach. Sustainability 2016, 8, 824. [CrossRef]

75. Pandey, D.; Kulkarni, M.S.; Vrat, P. Joint consideration of production scheduling, maintenance and quality policies: A review and conceptual framework. Int. J. Adv. Oper. Manag. 2010, 2, 1-24. [CrossRef]

76. Lindström, J.; Larsson, H.; Jonsson, M.; Lejon, E. Towards intelligent and sustainable production: Combining and integrating online predictive maintenance and continuous quality control. Procedia CIRP 2017, 63, 443-448. [CrossRef]

77. Tambe, P.P.; Kulkarni, M.S. A novel approach for production scheduling of a high pressure die casting machine subjected to selective maintenance and a sampling procedure for quality control. Int. J. Syst. Assur. Eng. Manag. 2014, 5, 407-426. [CrossRef]

78. Duffuaa, S.; Kolus, A.; Al-Turki, U.; El-Khalifa, A. An integrated model of production scheduling, maintenance and quality for a single machine. Comp. Ind. Eng. 2020, 142, 106239. [CrossRef]

79. Hill, D.C.; Seabrook, K.A. Safety \& sustainability: Understanding the business value. Prof. Saf. 2013, 58, 81-92.

80. Costella, M.F.; Dalcanton, F.; Cardinal, S.M.; Vilbert, S.S.; Pelegrini, G.A. Maintenance, occupational health and safety: A systematic review of the literature. Gestão Produção 2020, 27, e3922. [CrossRef]

81. Mwanza, B.G.; Mbohwa, C. Safety in Maintenance: An Improvement Framework. Proc. Manuf. 2017, 8, 657-664. [CrossRef]

82. Antosz, K. Maintenance-Identification and analysis of the competency gap. Eksploat. Niezawodn. 2018, 20, 484-494. [CrossRef]

83. Iheukwumere-Esotuand, L.O.; Kaltungo, A.Y. Assessment of Barriers to Knowledge and Experience Transfer in Major Maintenance Activities. Energies 2020, 13, 1721. [CrossRef]

84. Kans, M.; Campos, J.; Håkansson, L. A remote laboratory for Maintenance 4.0 training and education. IFAC PapersOnLine 2020, 53, 101-106. [CrossRef]

85. Bokrantz, J.; Skoogh, A.; Berlin, C.; Stahre, J. Maintenance in digitalised manufacturing: Delphi-based scenarios for 2030. Int. J. Prod. Econ. 2017, 191, 154-169. [CrossRef]

86. Franciosi, C.; Voisin, A.; Miranda, S.; Iung, B. Integration of I4.0 technologies with maintenance processes: What are the effects on sustainable manufacturing? IFAC PapersOnLine 2020, 53, 1-6. [CrossRef]

87. Nezami, F.G.; Yildirim, M.B. A sustainability approach for selecting maintenance strategy. Int. J. Sust. Eng. 2013, 6, 332-343. [CrossRef]

88. Yan, J.; Hua, D. Energy Consumption Modelling for Machine Tools After Preventive Maintenance. In Proceedings of the IEEE International Conference on Industrial Engineering and Engineering Management (IEEM), Macao, China, 7-10 December 2010; pp. 2201-2205.

89. Chen, J.; Zhang, R.; Wu, D. Equipment Maintenance Business Model Innovation for Sustainable Competitive Advantage in the Digitalization Context: Connotation, Types, and Measuring. Sustainability 2018, 10, 3970. [CrossRef]

90. Bocewicz, G.; Banaszak, Z.; Rudnik, K.; Witczak, M.; Smutnicki, C.; Wikarek, J. Milk-run routing and scheduling subject to fuzzy pickup and delivery time constraints: An ordered fuzzy numbers approach. In Proceedings of the IEEE International Conference on Fuzzy Systems, Glasgow, UK, 19-24 July 2020; p. 9177733. [CrossRef]

91. Thibbotuwawa, A.; Bocewicz, G.; Radzki, G.; Nielsen, P.; Banaszak, Z. UAV Mission Planning Resistant to Weather Uncertainty. Sensors 2020, 20, 515. [CrossRef]

92. Kotowska, J.; Markowski, M.; Burduk, A. Optimization of the supply of components for mass production with the use of the ant colony algorithm. In International Conference on Intelligent Systems in Production Engineering and Maintenance; Springer: Cham, Switzerland, 2017; pp. 347-357.

93. Karim, R.; Candell, O.; Söderholm, P. Development of ICT-based maintenance support services. J. Qual. Maint. Eng. 2009, 15, 127-150. [CrossRef]

94. Sun, B.; Zeng, S.; Kang, R.; Pecht, M. Benefits and Challenges of System Prognostics. IEEE Trans. Reliab. 2012, 61, 323-335. [CrossRef]

95. Huanga, J.; Changa, Q.; Arinezc, J.; Xiao, G. A Maintenance and Energy Saving Joint Control Scheme for Sustainable Manufacturing Systems. Procedia CIRP 2019, 80, 263-268. [CrossRef]

96. Yan, S.; MA, B.; Wang, X.; Chen, J.; Zheng, C. Maintenance policy for oil-lubricated systems with oil analysis data. Eksploat. Niezawod. 2020, 22, 455-464. [CrossRef] 
97. Jacobs, J.; Webber-Youngman, R.C.W. A technology map to facilitate the process of mine modernization throughout the mining cycle. J. S. Afr. I Min. Metall. 2017, 117, 636-648. [CrossRef]

98. Stock, T.; Seliger, G. Opportunities of Sustainable Manufacturing in Industry 4.0. Procedia CIRP 2016, 40, 536-541. [CrossRef]

99. Durán, O.; Macchi, M.; Roda, I. On the relationship of spare parts inventory policies with Total Cost of Ownership of industrial assets. IFAC-PapersOnLine 2016, 49, 19-24. [CrossRef]

100. Alqahtani, A.Y.; Gupta, S.M. Warranty and preventive maintenance analysis for sustainable reverse supply chains. J. Manuf. Sci. E 2017, 2, 69-94. [CrossRef]

101. Franciosi, C.; Lambiase, A.; Miranda, S. Sustainable maintenance: A periodic preventive maintenance model with sustainable spare parts management. IFAC-PapersOnLine 2017, 50, 13692-13697. [CrossRef]

102. Kumar, A.; Shankar, R.; Thakur, L.S. A big data driven sustainable manufacturing framework for condition-based maintenance prediction. J. Comput. Sci-Neth. 2018, 27, 428-439. [CrossRef]

103. Godichaud, M.; Tchangani, A.; Pérès, F.; Iung, B. Sustainable management of end-of-life systems. Prod. Plan. Con. 2012, 23, 216-236. [CrossRef]

104. Roda, I.; Macchri, M. Studying the funding principles for integrating Asset Management in Operations: An empirical research in production companies. IFAC-PapersOnLine 2016, 49, 1-6. [CrossRef]

105. Deloux, E.; Castanier, B.; Bérenguer, C. Predictive maintenance policy for a gradually deteriorating system subject to stress. Reliab. Eng. Syst. Saf. 2009, 94, 418-431. [CrossRef]

106. Duffuaa, S.O.; Ben-Daya, M.; Al-Sultan, K.S.; Andijani, A.A. A generic conceptual simulation model for maintenance systems. J. Qual. Maint. Eng. 2001, 73, 207-219. [CrossRef]

107. Turki, S.; Hajej, Z.; Rezg, N. Impact of Delivery Time on Optimal Production/Delivery/Maintenance Planning. In Proceedings of the IEEE International Conference on Automation Science and Engineering (CASE), Seoul, Korea, 20-24 August 2012; pp. 335-340.

108. Wang, W.Y. Optimum production and inspection modeling with minimal repair and rework considerations. Appl. Math. Model. 2013, 37, 1618-1626. [CrossRef]

109. Zhang, Y.; Ren, S.; Liu, Y.; Si, S. A big data analytics architecture for cleaner manufacturing and maintenance processes of complex products. J. Clean. Prod. 2016, 142, 626-641. [CrossRef]

110. Narayan, V. Business Performance and Maintenance: Ho ware Safety, Quality, Reliability, Productivity and Maintenance Related? J. Qual. Maint. Eng. 2012, 18, 183-195. [CrossRef]

111. Bouslah, B.; Gharbi, A.; Pellerin, R. Joint economic design of production, continuous sampling inspection and preventive maintenance of a deteriorating production system. Int. J. Prod. Econ. 2016, 173, 184-198. [CrossRef]

112. Glawar, R.; Karnera, M.; Nemeth, T.; Matyas, K.; Sihn, W. An approach for the integration of anticipative maintenance strategies within a production planning and control model. Procedia CIRP 2018, 67, 46-51. [CrossRef]

113. Bouslah, B.; Gharbi, A.; Pellerin, R. Joint production, quality and maintenance control of a two-machine line subject to operationdependent and quality-dependent failures. Int. J. Prod. Econ. 2018, 195, 210-226. [CrossRef]

114. Ajukumar, V.N.; Gandhi, O.P. Evaluation of green maintenance initiatives in design and development of mechanical systems using an integrated approach. J. Clean. Prod. 2013, 51, 34-46. [CrossRef]

115. Knowles, M. The role of maintenance in energy saving in commercial refrigeration. J. Qual. Maint. Eng. 2012, 18, 282-294. [CrossRef]

116. Savino, M.; Macchi, M.; Mazza, A. Investigating the impact of social sustainability within maintenance operations: An action research in heavy industry. J. Qual. Maint. Eng. 2015, 21, 310-331. [CrossRef]

117. Teymourian, K.; Seneviratne, A.M.N.B.; Galar, D. Ergonomics Contribution in Maintainability. Manag. Syst. Prod. Eng. 2017, 25, 217-223. [CrossRef]

118. Zhao, Y.; Lu, M.; Yuan, Y. Operation and maintenance integration to improve safety. Comp. Chem. Eng. 2000, $24,401-407$. [CrossRef]

119. Okoh, P.; Haugen, S. Maintenance-related major accidents: Classification of causes and case study. J. Loss. Prevent. Proc. 2013, 26, 1060-1070. [CrossRef]

120. Franciosi, C.; Di Pasquale, V.; Iannone, R.; Miranda, S. A taxonomy of performance shaping factors for human reliability analysis in industrial maintenance. J. Ind. Eng. Manag. 2019, 12, 115-132. [CrossRef]

121. Savolainen, P.; Magnusson, J.; Gopalakrishnan, M.; Turanoglu Bekar, E.; Skoogh, A. Organizational Constraints in data-driven Maintenance: A case study in the automotive industry. IFAC PapersOnLine 2020, 53, 95-100. [CrossRef]

122. Hu, Y.; Liu, S.; Zhang, H. Remanufacturing Decision Based on RUL Assessment. Procedia CIRP 2015, 29, 764-768. [CrossRef]

123. Lee, J.; Ni, J.; Djurdjanovic, D.; Qiu, H.; Liao, H. Intelligent prognostics tools and e-maintenance. Comp. Ind. 2006, 57, 476-489. [CrossRef]

124. Dombrowski, U.; Schulze, S.; Weckenborg, S. Life Cycle Costing as a Tool for effective Spare Parts Management. In Proceedings of the 16th CIRP International Conference on Life Cycle Engineering, Cairo, Egypt, 4-6 May 2009; pp. 478-483.

125. Do, P.; Hoang, A.; Iung, B.; Vu, H.-C. Energy efficiency for condition-based maintenance decision-making: Application to a manufacturing platform. Proc. Inst Mech. Eng. Part O J. Risk Reliab. 2018, 232, 379-388. [CrossRef]

126. Campos, J. Development in the application of ICT in condition monitoring and maintenance. Comp. Ind. 2009, 60, 1-20. [CrossRef]

127. Daily, J.; Peterson, J. Predictive Maintenance: How Big Data Analysis Can Improve Maintenance. In Supply Chain Integration Challenges in Commercial Aerospace; Richter, K., Walther, J., Eds.; Springer: Cham, Switzerland, 2017. 
128. Guillén, A.J.; Crespo, A.; Gómez, J.F.; Sanz, M.D. A framework for effective management of condition based maintenance programs in the context of industrial development of E-Maintenance strategies. Comp. Ind. 2016, 82, 170-185. [CrossRef]

129. Sari, E.; Shaharou, A.; Maaram, A.; Yazid, A.M. Sustainable maintenance performance measures: A pilot survey in Malaysian automotive companies. Procedia CIRP 2015, 26, 443-448. [CrossRef]

130. Amrina, E.; Yulianto, A. Interpretive Structural Model of Key Performance Indicators for Sustainable Maintenance Evaluation in Rubber Industry. IOP Conf. Mater. Sci. Eng. 2018, 319, 012055. [CrossRef]

131. Ashek-Al-Aziz, M.; Mahmud, S.; Islam, M.; Mahmud, J.A.; Hasib, K.M. A Comparative Study of AHP and Fuzzy AHP Method for Inconsistent Data. Int. J. Sci. Basic Appl. Res. 2020, 54, 16-37.

132. Machado, C.G.; Winroth, M.P.; de Silva, E.H.D.R. Sustainable manufacturing in Industry 4.0: An emerging research agenda. Int. J. Prod. Res. 2020, 58, 1462-1484. [CrossRef]

133. Felsberger, A.; Reiner, G. Sustainable Industry 4.0 in Production and Operations Management: A Systematic Literature Review. Sustainability 2020, 12, 7982. [CrossRef] 